\title{
Immunophenotyping of the Blast Cells in Correlations with the Molecular Genetics Analyses for Diagnostic and Clinical Stratification of Patients with Acute Myeloid Leukemia: Single Center Experience
}

\author{
Irina Panovska-Stavridis \\ University Clinic of Hematology, Skopje \\ Republic of Macedonia
}

\section{Introduction}

\subsection{Acute leukemias}

Acute leukemias are a heterogeneous group of malignancies that result from the malignant transformation of immature hematopoietic cells followed by clonal proliferation and accumulation of the transformed cells. They are characterized by aberrant differentiation and maturation of the malignant cells, with a maturation arrest and accumulation of more than $20 \%$ of leukemic blast in the bone marrow (Lichtman et al., 2010).

The natural history of acute leukemia and the response to therapy varies according to the type of blast involved in the leukemic process. Although in many instances the lineage assignment of the different types of blast cells may be recognized by simple morphological and cytochemical stains, it is necessary to employ immunological analyses with monoclonal antibodies and cytogenetic or molecular biological techniques to identify their particular differentiation features (Haferlach et al., 2007).

Acute leukemias are primarily characterized according to their differentiation along the myeloid and lymphoid lineage and they are divided into two main groups: acute myeloid leukemia (AML) and acute lymphoblastic leukemia (ALL). In $10 \%$ to $20 \%$ of patients, the leukemic cells have characteristics of both myeloid and lymphoid cells (Lichtman et al.,2010).

The classification of the acute leukemias underwent many changes in recent years. The FrenchAmerican-British (FAB) classification of AML and ALL was based on cytomorphological and cytohemistry details only. Since then, the diagnostic of acute leukemias had undergone a complete change and the routine diagnostic work-up incorporated immunophenotyping by multiparameter flow cytometry, classical cytogenetics, molecular cytogenetics (comprising diverse fluorescence in situ hybridization techniques and comparative genomic hybridization) and molecular genetics (mostly polymerase chain reaction (PCR)-based techniques and sequencing) (Bennet et al., 1997; First MIC Cooperative Study Group, 1985; Haferlach et al., 2007). 
According to the proceedings in diagnostic methods and the improved understanding of the diversity of acute leukemia subtypes, the latest World Health Organization (WHO) classification of acute leukemias incorporates and interrelates morphology, cytogenetics, molecular genetics and immunologic markers and pays major attention on the importance of genetic events in the classification, prognosis and therapy of the AMLs. Its prognostic relevance is most clearly demonstrated in the AMLs characterized by recurrent chromosome translocation: $t(15,17), t(8,21)$ and $\operatorname{inv}(16) / t(16,16)$ which generally have a favorable prognosis when treated with appropriate therapeutic agents. All other genetic events identified among AMLs had strong prognostic meaning but did not influence on the therapeutic decision (Swerdlow et al., 2008).

In the WHO classification of precursor B-cell and T-cell neoplasms, immunophenotying of the malignant cells plays a decisive role in the diagnosis, prognosis and clinical stratification of patients (Swerdlow et al., 2008).

Correct diagnosis of the diverse subtypes of AML and ALL play a central role for individual clinical risk stratification and therapeutic decisions.

\subsection{Acute myeloid leukemia}

Acute myeloid leukemia (AML) is one of the most common types of leukemia in adults. It is characterized by limited myeloid differentiation of the malignant cells. The malignant cells characteristically undergo maturation arrest at the level of the early myloblast or promyelocyte, although varying proportions of mature hematopoietic cells are leukemia derived. The cells that display myeloid markers include morphology, Auer rods (aberrant primary granules), cytochemistry (Sudan black, myeloperoxidase, or nonspecific esterase), and cell surface antigens (Lichtman et al., 2010).

AML encompasses a family of hematologic malignancies that can be categorized according to their cytogenetic and associated genetic abnormalities, which have major prognostic importance. During recent years, considerable progress has been made in deciphering the molecular genetics and epigenetic basis of AML and in defining new diagnostic and prognostic markers. A growing number of recurring genetic changes have been recognized in the new WHO classification of AML. Furthermore, novel therapies are now being developed that target some of the genetic lesions and the treatment increasingly is being individualized by prognostic groups, with a goal of developing treatment tailored to the molecular basis of the patient's malignancy (Swerdlow et al., 2008).

\subsubsection{WHO classification of AML}

The current WHO classification of AML reflects the fact that an increasing number of new clinico-pathologenetic entities of AML are categorized based upon their underlying cytogenetic or molecular genetic abnormalities (Swerdlow et al., 2008). A number of recurrent genetic abnormalities are adequately defined and are recognized as entities of AML. The subgroup "AML with recurrent genetic abnormalities" is comprised of entities that are defined with seven recurrent balanced translocations and inversions, and their

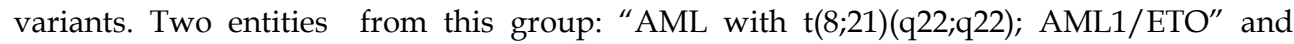
"AML with inv(16)(p13.1q22) or $\mathrm{t}(16 ; 16)(\mathrm{p} 13.1 ; \mathrm{q} 22)$; $\mathrm{CBF} \beta / \mathrm{MYH11}$ " are considered as AML regardless of bone marrow blast counts. In "APL with $t(15 ; 17)(q 22 ; q 12) ; P M L / R A R \alpha$," RAR $\alpha$ translocations with other partner genes are recognized separately. The former category "AML with 11q23 (MLL) abnormalities" is redefined in "AML with 
$\mathrm{t}(9 ; 11)(\mathrm{p} 22 ; \mathrm{q} 23) ;$ MLLT3/MLL", and now is a unique entity. Three new cytogenetically defined entities also are incorporated: "AML with $\mathrm{t}(6 ; 9)(\mathrm{p} 23 ; \mathrm{q} 34) ; \mathrm{DEK}-\mathrm{NUP} 214$ ", "AML with inv(3)(q21q26.2) or t(3;3)(q21;q26.2); RPN1-EVI1"; and "AML (megakaryoblastic) with $\mathrm{t}(1 ; 22)(\mathrm{p} 13 ; \mathrm{q13}) ; \mathrm{RBM15-MKL1,"} \mathrm{a} \mathrm{rare} \mathrm{leukemia} \mathrm{most} \mathrm{commonly} \mathrm{occurring} \mathrm{in} \mathrm{infants}$ (Vardiman et al., 2008).

Moreover, two new provisional entities defined by the presence of gene mutations between the group of cytogenetically normal AML (CN-AML) were added, "AML with mutated NPM1 (nucleophosmin)," and "AML with mutated CEBPA [CCAAT/enhancer binding protein(C/EBP), alpha]." There is growing evidence that these two gene mutations represent primary genetic lesions (so-called class II mutations), that impair hematopoietic differentiation, and when present alone in AML have favorable prognostic meaning. Mutations in the FMS-related tyrosine kinase 3 (FLT3) gene are found in many AML subtypes and are considered as class I mutations conferring a proliferation and/or survival advantage. AML with FLT3 mutations are not considered as a distinct entity, although determining the presence of those mutations is recommended by WHO because they have prognostic significance. The former subgroup termed "AML with multilineage dysplasia" is now designated "AML with myelodysplasia-related changes." Dysplasia in 50\% or more of cells, in 2 or more hematopoietic cell lineages, was the diagnostic criterion for the former subset (Schhlenk et al, 2008; Vardiman et al.,2008)

However, the clinical significance of this morphologic feature has been questioned. AMLs are now categorized as "AML with myelodysplasia-related changes" if (1) they have a previous history of myelodysplastic syndrome (MDS) or myelodysplastic/myeloproliferative neoplasm (MDS/MPN) and evolve to AML with a marrow or blood blast count of $20 \%$ or more; (2) they have a myelodysplasia-related cytogenetic abnormality; or (3) if $50 \%$ or more of cells in 2 or more myeloid lineages are dysplastic (Swerdlow et al., 2008).

"Therapy-related myeloid neoplasms" has remained a distinct entity; however, since most patients have received treatment using both alkylating agents and drugs that target topoisomerase II for prior malignancy, a division according to the type of previous therapy is not often feasible. Therefore, therapy-related myeloid neoplasms are no longer subcategorized. Myeloid proliferations related to Down syndrome are now listed as distinct entities (Döhner et al., 2010).

A previous FAB classification is recognized in WHO classification as the entity AML, not otherwise specified. In this subgroup one can find the morphologic separation of AML according to the immaturity of leukemic cells as well as according to the hematopoietic lineage involved. This subtype of AML is reserved for the patients without the known cytogenetic or molecular genetic abnormalities. In some of them, there are markers associated with prognostic significance (Swerdlow et al., 2008; Vardiman et al, 2008).

The rare forms of AML and acute leukemia of ambiguous lineage recognized in WHO classification are also associated with poor prognosis (Döhner et al., 2010; Vardiman et al., 2008).

\subsection{Diagnostic procedures}

The diagnosis of the diverse subtypes of AML is a major challenge for modern hematology. Modern therapeutic concepts of AML are based on individual risk stratification in diagnosis and during follow-up. In the 1970s cytomorphology and cytochemistry represented the only available diagnostic tools. Nowadays, the routine diagnostic setting is completely changed 
and it consists of classic cytogenetics, molecular cytogenetics, molecular genetics and immunophenotyping by multi-parameter flow cytometry (Döhner et al., 2010 ).

\subsubsection{Cytomorphology}

First steps in the diagnostic work-up of a patient with suspected AML is a morphological evaluation of a classical bone marrow aspirate and a peripheral blood smear by using a May-Grunwald-Giemsa or a Wright-Giemsa stain. It is recommended that at least 200 leukocytes on blood smears and 500 nucleated cells on marrow smears to be counted. For a diagnosis of AML, a marrow or blood blast count of $20 \%$ or more is required, except for AML with $t(15 ; 17), t(8 ; 21)$, inv(16) or $t(16 ; 16)$, and some cases of erythroleukemia. Myeloblasts, monoblasts, and megakaryoblasts are included in the blast count. Erythroblasts are not counted as blasts except in the rare instance of pure erythroid leukemia (Bennet et al,1997; Döhner et al., 2010; Panovska-Stavridis et al., 2008).

\subsubsection{Cytochemistry}

Lineage involvement could be identified with cytochemistry by using myeloperoxidase (MPO) or Sudan black B (SBB) and nonspecific esterase (NSE) stains. Detection of MPO (if present in $>3 \%$ of blasts) indicates myeloid differentiation, but its absence does not exclude a myeloid lineage because early myeloblasts and monoblasts may lack MPO. SBB staining parallels MPO but is less specific. NSE stains show diffuse cytoplasmic activity in monoblasts (usually $80 \%$ are positive) and monocytes (usually $20 \%$ positive). In acute erythroid leukemia, a periodic acid-Schiff (PAS) stain may show large globules of PAS positivity (Bennet et al,1997; Döhner et al., 2010, Panovska-Stavridis et al., 2008).

\subsubsection{Immunophenotyping}

Application of immunophenotyping together with the cytomorpohology and cytohemistry has a crucial role in the initial diagnosis of all cases with a suspected or proven diagnosis of acute leukemias. Immunophenotyping allows the discrimination of different cell population on the basis of their size, granularity, and antigen expression patterns. Flow cytometry is a powerful technology for characterization and analysis of cells. It simultaneously measures and analyzes multiple physical characteristics of single particles, usually cells, as they move in a fluid stream through a beam of light through an optical and/or electronic detection apparatus. Flow cytometry uses the principles of light scattering, light excitation, and emission of fluorochrome molecules to generate specific multi-parameter data from particles and cells in the size range of $0.5 \mathrm{~nm}$ to $40 \mathrm{~nm}$ diameter (Panovska-Stavridis et al., 2008).

The applied methodology detects cell surface antigens in a suspension of viable cells and cytoplasmic and nuclear antigens in previously fixed and stabilized cell suspension with the application of monoclonal antibodies conjugated with different fluorochromes. It permits simultaneous detection (multiparameter analyzes) of more than two membrane and nuclear or cytoplasmic antigens by means of double or multiple immunostaining (Bain et al., 2002; Bene et al., 1995; Döhner et al., 2010; Panovska-Stavridis et al., 2008).

\subsubsection{Cytogenetics}

Chromosome abnormalities are detected in approximately 55\% of adult AML. Conventional cytogenetic analyses are part of the standard diagnostic approach of a patient suspected with AML. This allows the identification of genetics entities that deserve targeted treatments 
like acute promyelocytic leukemia (APL). Also, it allows the distinction of the disease with widely different prognosis. For example AML $t(8 ; 21)(\mathrm{q} 22 ; \mathrm{q} 22)$ with favorable risk versus AML abn 3q26 with adverse risk (Döhner et al., 2010; Grimwade D.,2001).

\subsubsection{Molecular genetics}

Numerous genetic abnormalities that escape cytogenetic detection like gene mutations and gene expression abnormalities are more recently discovered among CN-AML. Molecular diagnosis by reverse transcriptase- polymerase chain reaction (RT-PCR) for the frequent gene fusions, such as AML1/ETO, CBFß/MYH11, MLLT3/MLL, DEK/NUP214, can also be useful in certain circumstances. RT-PCR, for which standardized protocols are already published, is also an excellent option to detect recurrent cytogenetic rearrangements, if chromosome morphology is of poor quality, or if there is typical marrow morphology but the suspected cytogenetic abnormality is not present. (Gabert et al., 2003; Beillard et al, 2003).

\subsection{Prognostic factors}

Prognostic factors of an AML case may be subdivided into those related to patient characteristics and general health condition and those related to characteristics particular to the AML clone. The former subset usually predicts treatment-related mortality (TRM) and becomes more important as patient age increases while the latter predicts resistance to, at least, conventional therapy.

\subsubsection{Patient-related factors}

Age, comorbidities, performance status and genetic variation in the drug metabolism are the main prognostic factors related to patients with AML. Increasing age is an important independent adverse prognostic factor (Appelbaum et al., 2006). Nonetheless, calendar age alone should not be a reason for not offering potentially curative therapy to an older patient because age is not the most important prognostic factor for either TRM or resistance to therapy. Currently all patients under the age of 60 are candidates to receive standard intensive chemotherapy and according to prognostic factors stem cell transplantation or intensive chemotherapy as postremission therapy. It has to be stressed that age as a factor is not only dependent on so-called "calendar age“. Recently many older patients with a good clinical status have been successfully treated with intensive chemotherapy. Attention should be given to a careful evaluation and documentation of comorbidities. Comorbidity scoring is a current field of investigation and should contribute to a better definition of the patient considered "unfit" for intensive chemotherapy (Piccirillo et al., 2004; Sorror et al., 2005).

\subsubsection{AML-related factors}

According to the AML working party of European Leukemia Net, several important and independent prognostic factors have been recognized: white blood cell counts, existence of prior MDS or AML with MDS features, previous cytotoxic therapy for another malignancy, and cytogenetic and molecular abnormalities in leukemic cells (Döhner et al., 2010).

\subsubsection{Cytogenetics}

Chromosome abnormalities are detected in approximately 55\% of adult AML. Although, there is a diversity of cytogenetic entities of AML, the karyotype of the leukemic cells is the strongest prognostic factor for response to induction therapy and for survival for AML patients 
(Swerdlow et al., 2008). Younger adult patients are commonly categorized into 3 risk groups, favorable, intermediate, or adverse. The favorable group is represented by the reciprocal translocations $\mathrm{t}(15 ; 17) / \mathrm{PML} / \mathrm{RAR} \alpha, \mathrm{t}(8 ; 21) / \mathrm{AML} 1 / \mathrm{ETO}$, and $\operatorname{inv}(16) / \mathrm{CBF} \beta / \mathrm{MYH} 11$, which are associated with a favorable prognosis In contrast, AML associated with $t(9 ; 11)(p 22 ; q 23)$ shows an inferior prognosis. These subgroups represent the first hierarchy of the WHO classification of AML, emphasizing that these subtypes represent distinct biologic entities. The second subgroup of AML patients shows a normal karyotype and an intermediate prognosis. However, from molecular aspects, this subgroup is very heterogeneous. Lately, there are emerging data suggesting that two genetics entities from this group, the AML with mutation of NPM1 gene without FLT3 mutations and AML with mutation in CEBPA gene should be moved from the intermediate prognosis group to the favorable group of AML. Those two entities are also added to the new WHO classification (Schlenk et al., 2008). The third (prognostically unfavorable) subgroup includes mostly unbalanced karyotypes characterized by a gain or loss of larger chromosomal regions. Within these, an especially complex aberrant karyotype, which occurs in $10 \%$ to $12 \%$ of patients and that is defined by $\geq 3$ chromosomal anomalies shows a very unfavorable prognosis. Cytogenetics is further helpful to delineate patients with therapy related AML (t-AML), who are classified as third hierarchy in the WHO classification, and developed either after treatment with alkylating agents often associated with cytogenetic aberrations involving $5 \mathrm{q}-,-7$, or p53 and complex aberrant karyotype or are showing MLL/11q23 or other balanced cytogenetic aberrations which are in frequent association to previous treatment with topoisomerase II inhibitors One striking observation is the increasing incidence of adverse versus favorable cytogenetic abnormalities with increasing age. This, at least in part, contributes to the poorer outcome of AML in older adults. (Byrd et al., 2002; Schlenk et al., 2008, Swerdlow et al., 2008)

\subsubsection{Molecular genetics}

Nowadays, considerable progress has been made in elucidating the molecular pathogenesis of acute leukemias that resulted in identification of new molecular diagnostic and prognostic markers. Gene mutations and deregulated gene expression have been identified that allow us to interpret the genetic diversity within defined cytogenetic groups, in particular the large and heterogeneous group of patients with CN-AML. Risk stratification by molecular markers in patients from the former group of AML plays an increasing role at diagnosis. The most relevant markers, which can be detected alone or in coincidence with other mutation are NPM1 mutations that is detected in approximately $40 \%$ of cases, MLLPTD in $6 \%$, NRAs in $8-10 \%$, CEBPA in $10 \%$ and FLT3-TKD mutations in $6 \%$ of CN-AML. Thus, a rather of limited number of markers further subclassifies more than $85 \%$ of $\mathrm{CN}$ AML. Data from the literature suggest that those markers have different prognosis regarding the outcome of the disease and they all indicate that in the near future molecular screening may allow " targeted allogeneic stem cell transplantation (alloSCT)" in AML patients with normal karyotype (Schlenk et al., 2008; Koreth et al, 2009).

There is a growing list of the new genetic abnormalities with clinical value that are being investigated. These genetic events perturb diverse cellular pathways and functions, and they often confer a profound impact upon the clinical phenotype of the disease and treatment response.

It is anticipated that advances in molecular technology will reveal additional markers that will result in more precise classification of this heterogeneous complex of disorders (Löwenberg B., 2008b; Haferlach T., 2008) 


\subsection{Treatment}

The parallel progress of the development of the diagnostic techniques improvement of the classification and therapeutical approach lead acute leukemia which were for the first time described before 150 years, and in the 1970s were still fatal disease nowadays to have overall 5 years survival rates of up to $40 \%$. (Appelbaum et al, 2001).

Despite heterogeneity of the disease, with the exception of acute promyelocytic leukemia, this disease has been treated with a "one size fits all" approach. Although, the vast majority of AML patients can be individually characterized on the basis of the distinct chromosomal aberrations and molecular markers, treatment of AML is still based on quite unspecific cytotoxic therapy. For almost 40 years, the use of continuous infusion of cytarabine combined with another agent, usually an anthracycline, the " $3+7$ " regimen, has been the mainstay of therapy (Yates et al, 1973). Response rates for induction with standard chemotherapy ranged from $70 \%$ to $80 \%$ for adults aged less than 60 years which are enrolled in clinical trials and average in $50 \%$ for patients older than 60 years (Lichtman et al.,2010) .

Alternative consolidation therapies by applying additional chemotherapy, autologous stem cell transplantation (autoSCT) or alloSCT based on the initial cytogenetic and molecular studies are available (Cornelissen J.J.et al.(2007); Fernandez H.F.,2010; Koreth et al, 2009)

As more sophisticated molecular techniques have become available, it is clear that it is still possible to detect residual disease when all morphological and functional criteria for remission are met. Techniques such as "real-time"-quantitative polymerase chain reaction (RQ-PCR) are capable of detection at a level of 1 in $10^{4}$ or 1 in $10^{5}$ residual cells, but such markers are available for only a minority of cases in which the molecular lesion has been characterized(Freeman et al., 2008).

AlloSCT is the most effective antileukemic modality that is characterized by immune mediated graft-versus-leukemia effect of the transplanted cells that reduce the risk of relapse considerably and improve the relapse-free survival but also is associated with the increased risk of death and morbidity. Therefore, the alloSCT advantage has to be carefully balanced against the excess mortality (ranging between $10 \%$ and $40 \%$ ) and morbidity due to transplantrelated complications, such as infection and graft-versus-host disease that are typically connected with alloSCT and can diminish all of the benefit of a reduced risk of relapse. (Cornelissen et al., 2007). For this reason, allogeneic stem cell transplantation is usually avoided in a type of AML that has a pattern of cytogenetics with a relatively favorable prognosis, such as AML with the chromosomal translocations $t(8 ; 21)$ or $\operatorname{inv}(16) / t(16 ; 16)$ (Marcucci et al., 2000; Perea et al.,2006). In the latter subtypes the risk of relapse is in the order of $35 \%$ to $40 \%$ or less. By contrast, a transplant is treatment of choice for all other patient whose leukemia cells bear a cytogenetic or molecular abnormality that predicts a high or intermediate risk of relapse after chemotherapy (Löwenberg et al., 2008b; Koreth et al, 2009). Exception could be done for two additional genotypically defined subsets of AML that are categorized as low-risk within the large category of CN-AML. Each of those entities has a risk of relapse of about 35\%. The first genotype is defined by the presence of 'favorable' mutations in NPM1 and the absence of concurrent 'unfavorable' FLT3-internal tandem duplications (NPM1mut / FLT3-ITDneg).61 This genotype accounts for approximately 16\% of all newly diagnosed patients younger than 60 years old. There is no demonstrable benefit from transplantation in patients with NPM1mut/FLT3-ITDneg AML. The second subset of AML with 'favorable' mutations in the transcription factor gene CEBPA (CEBPAmut) could not be analyzed in this way because of a lack of statistical power due to a limited number of cases. The latter low-risk subtype CEBPAmut accounts for $8 \%$ of all AML. Nevertheless, the 
available body of evidence suggests that these AMLs are unlikely to profit from an alloSCT (Schlenk et al., 2008).

Thus, it could be concluded that patients with AML with $t(8 ; 21)$, AML with inv(16)/t(16;16), AML with NPM1mut/ FLT3-ITDneg and AML with CEBPA mutations should not considered for alloSCT. Nevertheless, it is important to stress that sufficient evidence so far exist only for the AML with recurrent cytogenetic abnormalities and the benefits for the two additional genetic low-risk AML entities should be validated in the larger studies in the future (Schlenk et al., 2008).

In the near future these results will also need to be considered more specifically in the light of the extended scale of allogeneic stem cell transplantation strategies with respect to reduced-intensity conditioning regimens and in relationship to different transplant sources and donor types (matched unrelated and haploidentical donors, umbilical stem cell grafts).(Löwenberg et al, 2008a)

\section{Motivation and aim of the study}

Correct diagnosis of the diverse subtypes of acute myeloid leukemia (AML) and acute lymphoblastic leukemia (ALL) play a central role for individual clinical risk stratification and therapeutic decisions. Modern therapeutic concepts of AML are based on individual risk stratification at diagnosis and during follow-up. The ultimate test of any disease diagnostic algorithm approach is its usefulness in guiding the selection of effective treatment strategies. (Haferlach et al., 2007, Löwenberg et al, 2008b) As discussed above, cytogenetic as well as various genomic markers (gene mutations, gene overexpression) may provide input for algorithms for remission induction and post-remission treatment decisions. At the same time, it remains appropriate to realize that prognostic factors in fact remain a moving target and they are only relevant to therapies available at a given time. Algorithms that provide a basis for risk-adapted therapeutic choices may include immunological markers, cytogenetic factors, molecular markers as well as clinical parameters (e.g., age, attainment of an early or late complete remission) and hematological determinants (e.g., secondary AML, white blood cell count at diagnosis).

On the other hand, the more carefully AML is studied, the clearer it becomes that there is considerable heterogeneity between cases with respect to morphology, immunological phenotype, associated cytogenetic and molecular abnormalities and, more recently, patterns of gene expression. This is reflected in the substantially different responses to treatment. Some entities are becoming so distinct that they are regarded as different diseases with specific approaches to treatment.

In order to improve and simplify the diagnosis and management of AML patients that are diagnosed and treated at the at the University Clinic of Hematology-Skopje we conducted a prospective study to establish and standardize a diagnostic algorithm based on minimal screening tests which will facilitate risk adapted therapy for each single AML patient. The aims of our study were: first, to establish the correct lineage assignment of the blast cells, second, to evaluate the incidence of the favorable genetic markers PML/RAR $\alpha$, AML1/ETO and CBF $\beta /$ MYH11 among the AML cases, then to correlate the obtained results with the patient age, comorbidities, and performance status and consecutively to select the effective treatment strategy for each single acute leukemia patient. 


\section{Material and methods}

\subsection{Patients and samples}

A total of 76 adult ( $>15$ years) patients (from initially 77 tested) with acute leukemia who were consecutively admitted at the Clinic of Hematology-Skopje from January through December 2008 were enrolled in this study. The median age of the patients (41 men, 35 women) was $52 \pm$ 18.66 years (range 16-80), and most of the patients 37 (48.7\%) were between 55 and 75 years old. The diagnosis was made by standard morphological examination and cytochemical analyses of bone marrow smears according to the criteria established by the FAB Cooperative Study Group (Bennet et al, 1997) and confirmed by immunophenotyping of bone marrow aspirates and/or peripheral blood samples (Bain et al., 2002; Bene et al., 1995 ) following the criteria of the European Group for the Immunological Classification of leukemias (EGIL) and the British Committee for Standards in Hematology (BCSH) (Bain et al., 2002; Bene et al., 1995). Consecutively, patients were further stratified in the adequate genetic AML entities according to the results of the molecular analyses. The samples contained more than $20 \%$ of blast cells (most of which had more than $50 \%$ ). All patients were tested for the presence of the fusion transcript of the mayor recurrent cytogenteic abnormalities in AML (PML/RAR $\alpha$, AML1/ETO, CBF $\beta /$ MYH11) by RT-PCR, according to standard procedures. (Gabert et al.2003; Beillardet al, 2003).

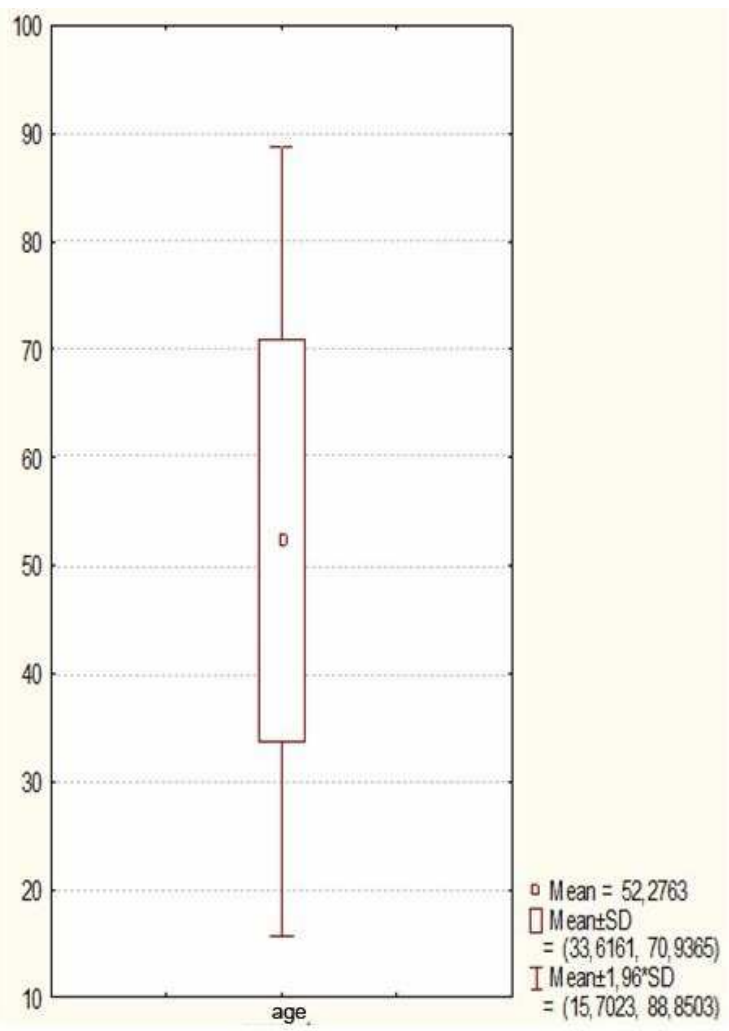

Fig. 1. Average age of the patients in the study group 


\subsubsection{Clinical data from the patients}

Clinical data from the patients were collected according the internal protocol that was approved by the University Clinic of Hematology Institutional Review Board. All included patients had to sign a written consent.

\subsection{Morphology}

The morphology was analyzed by microscopic examination of $>500$ nonerythroid cells on May Gruenwald Giemza stained air-dried bone marrow smears (Bennet et al,1997; Döhner et al., 2010; Panovska-Stavridis et al., 2008).

\subsection{Cytochemical analysis}

Air-dried bone marrow smears were stained for MPO, non specific esterase (NSE) and periodic acid-Schiff (PAS) according to the manufacturers guidelines. The percentage of positive cells for either stain was assessed by microscopic examination of 200 nonerythroid cells (Bennet et al, 1997; Döhner et al., 2010; Panovska-Stavridis et al., 2008).

\subsection{Immunophenotyping}

The muliparameter flow cytometry (MPF) was performed at the beginning at the Institute for Immunobiology and Human Genetics, Faculty of Medicine-Skopje and then continued at the University Clinic of Hematology-Skopje. Immunophenotyping was done first, by using Cytomation (DAKO-Cytomation) flow-cytometer and than by BD FACSCanto ${ }^{\mathrm{TM}}$ II analyzer, on whole blood and/or bone marrow specimens using lysing solutions (BD-Biosciensies, San Jose.CA. USA)(Bain et al., 2002). We prepare the samples for simultaneous detection of three cytoplasmic/nuclear and membrane antigens. The first step involved immunostaining of cell suspension with multiple panels of tree monoclonal antibodies (McAb) labeled with fluorescein (FITC), phycoerythrin (PE) and phycoerythryn-Cy5 tandem complex (Pe-Cy5) as third color (Panovska-Stavridis et al., 2008). The slightly modified panel of monoclonal antibodies (McAb) against myeloid- and lymphoid-associated antigens as suggested by the EGIL was utilized (Bain et al., 2002; Panovska-Stavridis et al., 2008). The antibodies and their manufacturers are listed in Table 1.

\begin{tabular}{|c|c|c|c|c|}
\hline & B-lineage & T-lineage & Myeloid markers & $\begin{array}{l}\text { Non-lineage } \\
\text { restricted }\end{array}$ \\
\hline First line & $\begin{array}{c}\text { CD19, } \\
\text { cyt CD79b, } \\
\text { cyt CD22 }\end{array}$ & $\begin{array}{l}\text { CD 2, CD7, } \\
\text { cyt CD3 }\end{array}$ & $\begin{array}{c}\text { CD117,CD13, } \\
\text { CD33,CD14, CD15, } \\
\text { anti-MPO, } \\
\text { anti-lisosyme }\end{array}$ & $\begin{array}{c}\text { TdT, CD34, } \\
\text { HLA-DR, CD } 56\end{array}$ \\
\hline Second line & $\begin{array}{c}\text { SmIg } \\
(\text { kappa/lambda)**, } \\
\text { cytIgM }^{2}, \text { CD138 }\end{array}$ & $\begin{array}{c}\text { CD1a,mCD31, } \\
\text { CD4,CD5,CD8, } \\
\text { anti TCR } \alpha / \beta, \\
\text { anti TCR } \gamma / \delta * * *\end{array}$ & $\begin{array}{c}\text { CD41, CD61, } \\
\text { CD42,CD71 } \\
\text { Anti-glycophorin A }\end{array}$ & CD38 \\
\hline
\end{tabular}

All markers were manufactured by BD-Biosciences, except antilysozyme (DAKO); 1.cyt: cytoplasmic; 2.m: membrane *MPO: myloperoxidase;** SmIg:surface immunoglobulin;*** TCR:T cell receptor

Table 1. Panel of monoclonal antibodies $(\mathrm{McAb})$ for diagnosis of acute leukemias 
For the detection of cytoplasmic and nuclear antigens we used commercially available permeabilization/fixation solutions (FACS Permeabilization solution BDBiosciencies;San Jose.CA.USA) ((Bain et al., 2002).

We incubated $100 \mathrm{ml}$ of specimens (peripheral blood or bone marrow) and appropriate $\mathrm{McAb}$ for $15 \mathrm{~min}$ at room temperature, than added the permeabilization solutions and/or lysing solution and repeated the incubation procedure. After the incubation we washed the samples three times with PBS-A, than re-suspended the cell with isotones solution and acquired the data. As control we used a lysed, but unstained sample (Panovska-Stavridis et al., 2008)

Acquired data were analyzed with software by using CD45 gating strategy (Borowitz et al, 1993). This technique involves incubation of all samples with fluorochrome - labeled CD45 $\mathrm{McAb}$ and with the McAb for which reactivity needs to be established with an alternative fluorochrome). In the initial step of the analyses, gating was set up on a CD45-positive versus light side-scatter dot plot. The procedure allowed the discrimination between the blast cell population and normal cells and the exclusion of platelets and debris. Thereafter, if necessary, it was possible to perform another gating, to separate the cells positive with the $\mathrm{McAb}$ under study (Borowitz et al, 1993). Leukemias were first screened by the primary panel and, if necessary, further characterized by the McAb of the secondary panel (Bain et al., 2002).

Antigen expression was considered positive if $20 \%$ or more blast cells reacted with a particular antibody, except reactivity of blasts cells with MPO. It was considered positive if $10 \%$ or more of mononuclear cells were MPO positive (Bain et al., 2002; Döhner et al., 2010).

\subsection{Molecular analysis}

Mononuclear cell preparation, RNA isolation, and cDNA synthesis were performed at the Department of Molecular Biology, Immunology and Pharmacogenetics, Faculty of Pharmacy-Skopje, according to standard procedures. Aliquots of $5 \mu \mathrm{L}$ of cDNA (100 ng RNA equivalent) were used for Real-time Quantitative polymerase chain reaction (RQ-PCR) with primers and dual-labeled probes as described by Gabert et al. Positions and nucleotide sequences of the primers and probes are shown in Table 2.

The RQ-PCR reaction was performed in a 25- $\mu$ l reaction volume using $12.5 \mu \mathrm{l}(1 \mathrm{x})$ Master Mix (Applied Biosystems), 300nM primers and 200nM probes on a Mx3005P(TM) QPCR System (Stratagene) under the following conditions: $95^{\circ} \mathrm{C}$ for $10 \mathrm{~min}$, followed by 50 cycles of $95^{\circ} \mathrm{C}$ for $15 \mathrm{~s}, 50^{\circ} \mathrm{C}$ for $1 \mathrm{~min}$. In order to correct variations in RNA quality and quantity and to calculate the sensitivity of each measurement, a control gene (CG) transcript was amplified in parallel to the fusion gene (FG) transcript. Since ABL (Abelson) gene transcript expression did not differ significantly between normal and leukemic samples, ABL was used as a control gene in this study (24). Positions and nucleotide sequences of the primers and probe are shown in Table 2.

\subsection{Statistical analysis}

Statistical analyses were performed by using the statistical analyses software SPSS 18.0 and by applying the Descriptive statistics (cross tabulation, frequencies, descriptive ratio statistics), bivariate statistics (means, t-test, correlation (bivariate, partial, distances), nonparametric tests and linear regression statistical methods. The Level of probability for obtaining the null hypothesis, in accordance with the international conventions for biomedical sciences was 0.05 or 0.01 (Armitage et al., 2002). 


\begin{tabular}{|c|c|c|c|}
\hline Transcript & EAC code & $\begin{array}{l}\text { Primer/probe } \\
\text { localization, } \\
5 \text { '-'3' position } \\
\text { (size) }\end{array}$ & Sequence \\
\hline \multirow[t]{3}{*}{$\begin{array}{l}\text { AML1 } \\
/ \text { ETO }\end{array}$} & ENF701 & $\begin{array}{l}\text { AML1, 1005-1026 } \\
(22)\end{array}$ & 5'-CAC CTA CCA CAG AGC CAT CAA A-3' \\
\hline & ENR761 & ETO, 318-297 (22) & 5'-ATC CAC AGG TGA GTC TGG CAT T-3' \\
\hline & ENP747 & $\begin{array}{l}\text { AML1, 1049-295 } \\
\text { (30) }\end{array}$ & $\begin{array}{l}\text { FAM 5'-AAC CTC GAA ATC GTA CTG AGA AGC } \\
\text { ACT CCA-3' TAMRA }\end{array}$ \\
\hline \multirow[t]{5}{*}{$\begin{array}{l}\text { PML } \\
\text { /RARa }\end{array}$} & ENF905 & $\begin{array}{l}\text { PML, 1198-1216 } \\
\text { (19) }\end{array}$ & 5'-CCG ATG GCT TCG ACG AGT T-3' \\
\hline & ENF906 & $\begin{array}{l}\text { PML, 1642-1660 } \\
\text { (19) }\end{array}$ & 5'-ACC TGG ATG GAC CGC CTA G-3' \\
\hline & ENF903 & $\begin{array}{l}\text { PML, 1690-1708 } \\
\text { (19) }\end{array}$ & 5'-TCT TCC TGC CCA ACA GCA A-3' \\
\hline & ENR962 & $\begin{array}{l}\text { RARA, } 485-465 \\
(21)\end{array}$ & 5'-GCT TGT AGA TGC GGG GTA GAG-3' \\
\hline & ENR942 & $\begin{array}{l}\text { RARA, } 439-458 \\
(20)\end{array}$ & FAM 5'-AGT GCC CAG CCC TCC CTC GC-3' TAMRA \\
\hline \multirow{5}{*}{$\begin{array}{l}\mathrm{CBF} \beta \\
/ \mathrm{MYH} 11\end{array}$} & ENF803 & CBFB, 389-410 (22) & 5'-CAT TAG CAC AAC AGG CCT TTG A-3' \\
\hline & ENR862 & $\begin{array}{l}\text { MYH11, 1952-1936 } \\
(17)\end{array}$ & 5'-AGG GCC CGC TTG GAC TT-3' \\
\hline & ENR863 & $\begin{array}{l}\text { MYH11, 1237-1217 } \\
\text { (21) }\end{array}$ & 5'-CCT CGT TAA GCA TCC CTG TGA-3' \\
\hline & ENR865 & $\begin{array}{l}\text { MYH11, 1038-1016 } \\
\text { (23) }\end{array}$ & 5'-CTC TTT CTC CAG CGT CTG CTT AT-3' \\
\hline & ENPr843 & CBFB, 434-413 (22) & $\begin{array}{l}\text { FAM 5'-TCG CGT GTC CTT CTC CGA GCC T-3' } \\
\text { TAMRA }\end{array}$ \\
\hline \multirow[t]{3}{*}{$\mathrm{ABL}$} & ENF1003 & ABL, 372-402 (31) & 5'-TGGAGATAACACTCTAAGCATAACTAAAGGT-3' \\
\hline & ENF1063 & ABL, 495-515 (21) & 5'-GATGTAGTTGCTTGGGACCCA-3' \\
\hline & ENF1043 & ABL, 467-494 (28) & $\begin{array}{l}\text { FAM 5'-CCA TTT TTG GTT TGG GCT TCA CAC CAT } \\
\text { T-3' TAMRA }\end{array}$ \\
\hline
\end{tabular}

Table 2. Sequences and positions of the RQ-PCR primers and probes

\section{Results}

In the period of twelve months, between January and December 2008, 77 patients were submitted and tested for acute leukemia at the University Clinic of Hematology-Skopje. Cyto-morphological analyses showed that the average rate of the blast cells in the differential blood counts and in the bone marrow was 54.6\%(3-99.0\%) and 73,5\%(20-98.0\%) respectively. In 7 patients blast cells were not detected initially. 


\subsection{Results from the cytochemical analyses}

Results from the cytochemical analyses and the images of peripheral smears with positive examples from different cytochemical staining are presented at Figure 2 and Photo 1 respectively.

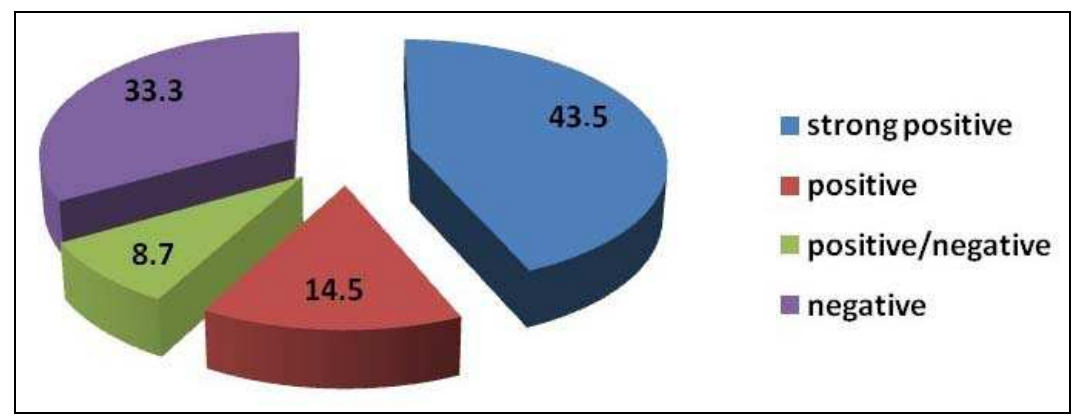

A

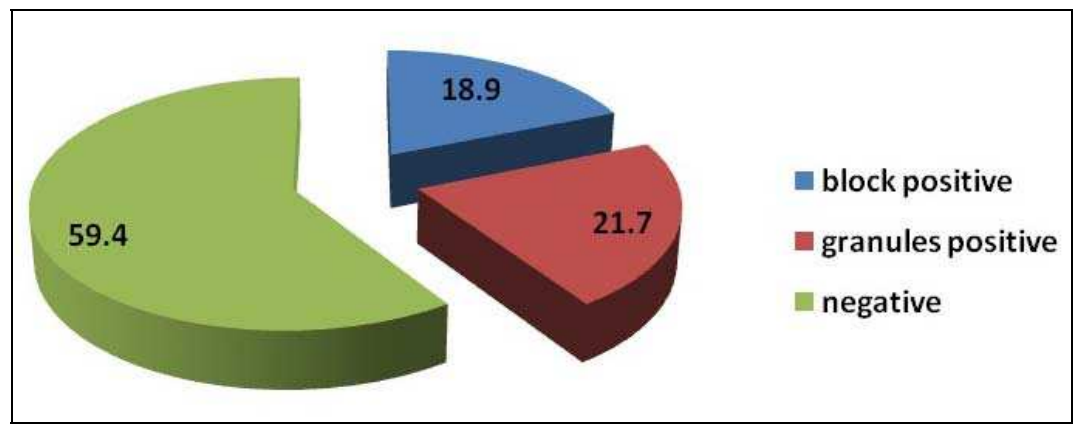

B

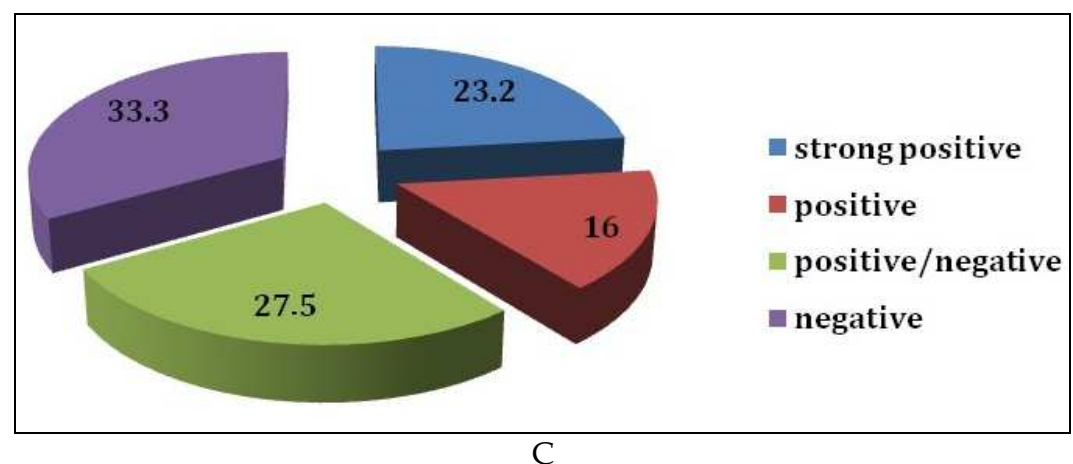

Fig. 2. Distribution of patients according to reactivity with different cytochemial staining. A:Patient distribution according to MPO reactivity of the blasts cells. B: Patient distribution according to PAS reactivity of the blasts cells. C: Patient distribution according to NSE reactivity of the blasts cells. 


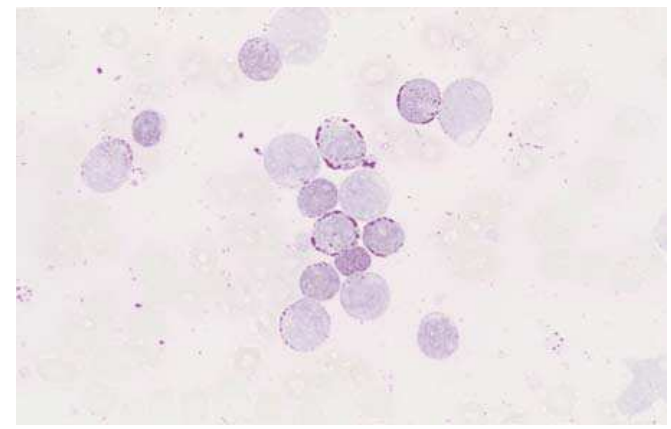

A

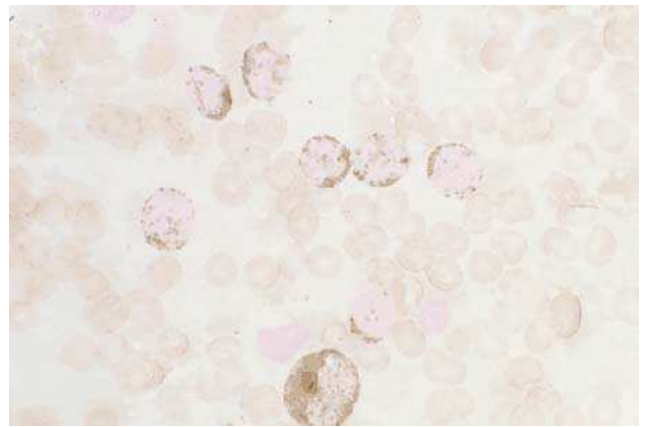

B

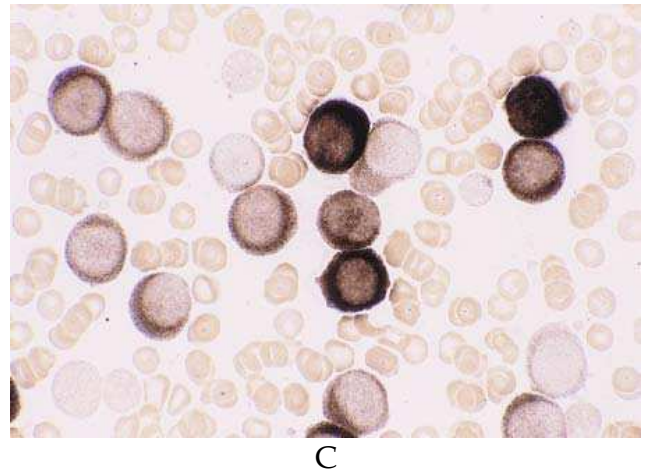

Photo 1. Images from positive reactivity of peripheral blast cells with different cytochemical staining , A: PAS reactivity, B: POX reactivity, C: NSE reactivity

Statistical analyses showed that there is a statistically significant correlation between the AML and MPO positivity ( $\mathrm{X}^{2}$ with Yates's correction=16.628 $\left.\mathrm{p}<0.01\right)$ (Figure 2A). According to cross reaction ratio, MPO positivity presents statistically significant risk which improves the chance of AML diagnosis for 39 times (OR=392.1603 (4.177<0R<305.9796, CI 95\%)). Also, a statistically significant correlation was noted between the PAS positivity and ALL ( $\mathrm{X}^{2}$ with Yates's correction $=5.514 \mathrm{p}<0.01$ )( Figure $2 \mathrm{~B}$ ). Strong PAS positivity was registered in $75 \%$ of ALL cases. Regarding the cytochemical stain NSE and AML no statistical correlation was 
observed $\left(\mathrm{X}^{2}\right.$ with Yates's correction=2.456 $\left.\mathrm{p}=0.117\right)$, expect for AML M4 and M5 entities which showed statistically significant correlation $(p<0,05)$ (Figure $2 \mathrm{C}$ ).

Morphology and cytochemistry established myeloid lineage in 57 (74.0\%) cases and lymphoid differentiation in $11(14.3 \%)$ cases (Figure 2). Morphology and cytochemistry did not establish lineage involvement in $9(11.7 \%)$ cases. Basic morphological and cytochemical analyses established the lineage assignment of the blasts cells in $68(88.3 \%)$ patients.

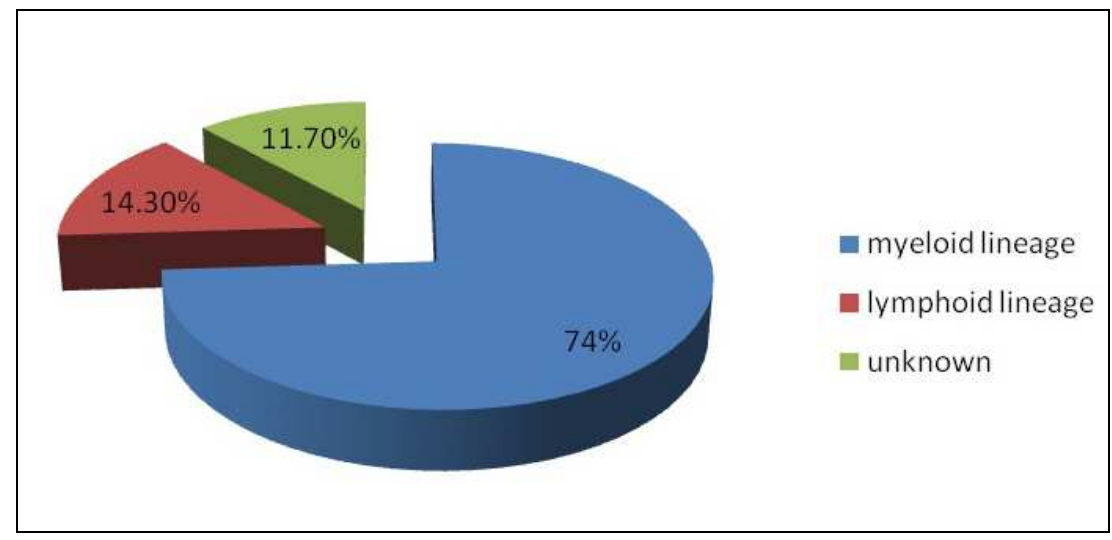

Fig. 3. Distribution of cases based on lineage assignment of blasts cells detected with basic morphological and cytochemial analyses

\subsection{Results from the immunological analyses}

Immunological analyses with multi-parameter flow-cytometry were performed in all 77 patients. Further immunological analyses of cases in which lineage could not be assigned based on morphology and cytochemistry established myeloid lineage in 4 patients, (AMLM0) and one case indicated nonhematopoietic malignancy. In this case, immunophenotype of the malignant cells (CD45-/CD56+/CD9+) indicated a neuroectodermal origin of the malignant cells (Bain et al., 2002). Later neuroblastoma was diagnosed in this patient. Immunological analyses change the assigned lineage based on morphology and cytochemistry in $3(3.8 \%)$ of the patients from lymphoid to myeloid. The results of our study showed that routine immunophenotyping improved diagnosis in $12(15.5 \%)$ cases.

Consequently, based on FAB and immunologic criteria of EGIL and BTSH 64 acute leukemias were classified as myeloid. Correlation between the antigen expressions with FAB morphology of AML cases which confirmed the AML diagnosis in $83.1 \%$ of the cases is presented at Table 3. According to FAB criteria, the leukemias were classified as M0 $(n=4)$, M1 ( $n=8)$, M2 ( $n=20)$, M3 ( $n=5)$, M4 ( $=17)$, M4-Eo ( $n=1)$, M5 ( $=8)$, M6 ( $n=1)$.

Multivariate Cox-proportional regression analyses showed that in $89.7 \%$ of AML cases lineage assignment is defined with the following five markers: CD13, CD33, CD117, HLADR and anti-MPO. Most frequently detected maturation myeloid marker which was expressed in $42.9 \%$ of AML case was CD15. Twenty three (35.9\%) of AML patients showed expression of lymphoid antigens. Co-expression of two lymphoid markers was detected in eleven $(17.1 \%)$ cases, and most frequently co-expressed lymphoid marker was CD7 and was detected in $28.5 \%$ of the cases. 


\begin{tabular}{|c|c|c|c|c|c|c|c|c|c|c|c|}
\hline 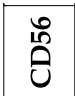 & চூర & 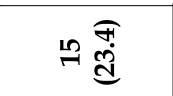 & & 0 & $r$ & $\Lambda$ & $N$ & $m$ & 0 & $N$ & 0 \\
\hline$\vec{\partial}$ & カુ & $m \stackrel{\widehat{\sigma}}{\stackrel{+}{+}}$ & & 0 & 0 & $N$ & 0 & 0 & - & 0 & 0 \\
\hline$\hat{\theta}$ & تే' & 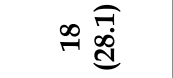 & & -1 & $\sigma$ & 0 & $N$ & 0 & $r$ & 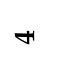 & 0 \\
\hline ิิ & ఫુ & 윰 $\stackrel{0}{\stackrel{0}{g}}$ & & 0 & $r$ & 0 & $r$ & in & 0 & m & 0 \\
\hline E & ठే & $\infty \stackrel{\text { ป }}{\text { n }}$ & & $N$ & $m$ & $r$ & 0 & 0 & $N$ & 0 & 0 \\
\hline 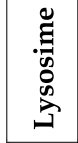 & ఫో & m & & 0 & 0 & 0 & $r$ & $\stackrel{N}{\sim}$ & $r$ & $\Lambda$ & 0 \\
\hline $\begin{array}{l}0 \\
\dot{z}\end{array}$ & छூ & + & & Fr & 0 & $\stackrel{\infty}{\sim}$ & 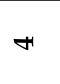 & $\stackrel{N}{\sim}$ & $r$ & $r$ & 0 \\
\hline 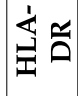 & تే & டin & & $\nabla$ & $\Lambda$ & 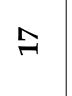 & $r$ & $\stackrel{0}{\Rightarrow}$ & $r$ & $\infty$ & - \\
\hline ठే & ర్ర & 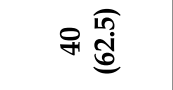 & & 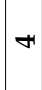 & 6 & $\stackrel{0}{=}$ & $N$ & $a$ & 0 & $N$ & $r$ \\
\hline 它 & ఫే & $\ln \stackrel{\infty}{\Xi}$ & & 0 & $N$ & $r$ & 0 & $r$ & 0 & $r$ & 0 \\
\hline ڤ̊ & రో & 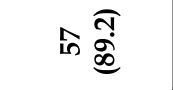 & & $N$ & $\infty$ & $\stackrel{\infty}{\rightarrow}$ & $r$ & $\stackrel{0}{=}$ & $r$ & $\Lambda$ & -1 \\
\hline 号 & ઇే & 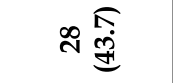 & & 0 & 0 & 0 & $\vec{H}$ & $\infty$ & $r$ & $a$ & 0 \\
\hline$\stackrel{\ddot{\theta}}{\vec{\theta}}$ & రే & 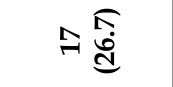 & & 0 & 0 & $r$ & 0 & $\infty$ & $r$ & $\Lambda$ & 0 \\
\hline$\stackrel{m}{\vec{\theta}}$ & రే & î & & $r$ & $\Lambda$ & $\stackrel{2}{\rightarrow}$ & r & $\stackrel{L}{\longrightarrow}$ & $r$ & $\Lambda$ & -1 \\
\hline$\stackrel{\vec{\theta}}{\vec{\theta}}$ & ఈ゙ & in & & $N$ & $\Lambda$ & શ્તి & 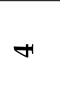 & $\mathbb{Z}$ & $r$ & 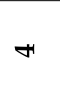 & -1 \\
\hline ใิ & ర్ర & $B \stackrel{\overbrace =}{\stackrel{\overbrace{}}{g}}$ & & $\theta$ & $\infty$ & $\bar{\lambda}$ & 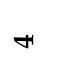 & $\approx$ & $r$ & $a$ & 0 \\
\hline & 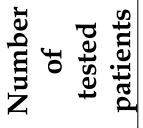 & 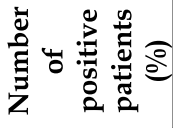 & 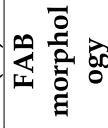 & 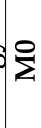 & $\sum$ & కี & $\sum^{m}$ & $\sum^{\mathbb{E}}$ & 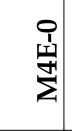 & $\sum^{n}$ & $\stackrel{0}{\Sigma}$ \\
\hline
\end{tabular}

Table 3. Correlation between the antigen expressions with FAB morphology of AML cases 


\subsection{Results from the molecular analyses}

Molecular evaluation of AML cases demonstrated presence of the three major recurrent genetic abnormalities as follows: 5 patients were positive for the fusion transcript PML/RAR $\alpha$ (Figure 5), 3 patients were positive for AML/ETO1 and 7 for the fusion transcript CBF $\beta / \mathrm{MYH} 11$ (Figure 4).

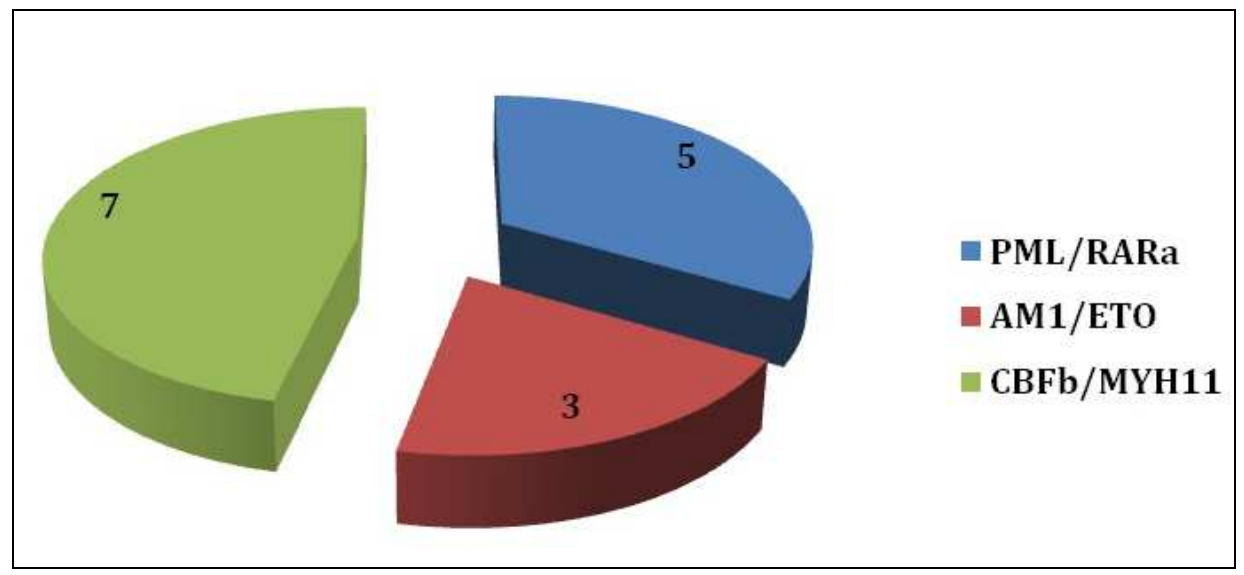

Fig. 4. Distribution of molecular abnormalities detected with the RQ-PCR assay in the group of AML patients;

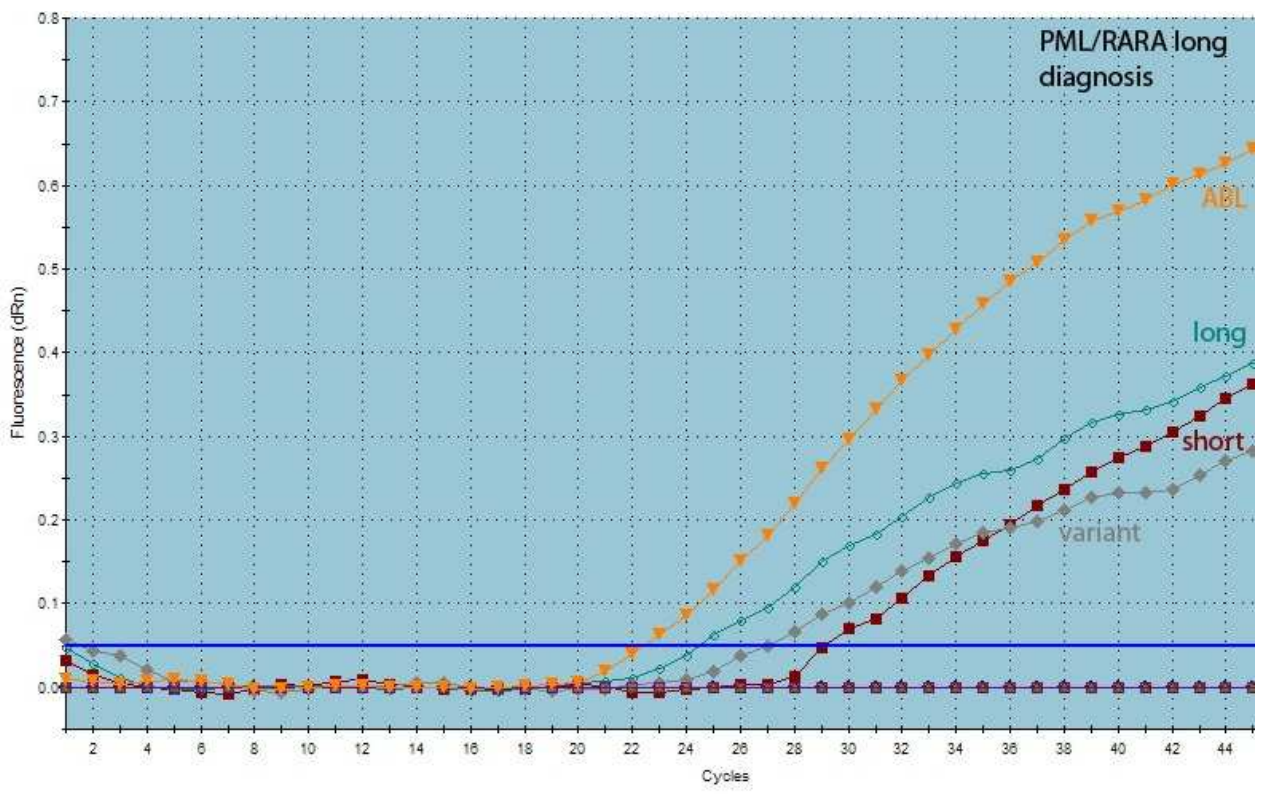

Fig. 5. Detection of fusion transcript PML/RAR $\alpha$ using the RQ-PCR method 
In 5 of the AML case PML/RAR $\alpha$ fusion transcript was detected. Four of those patients had morphology and immunophenotype that correlate with AML-M3 diagnosis. The five patients were first diagnosed as AML-M2 and only after the positive result for PML/RAR $\alpha$ the diagnosis was revised as AML-M3. In all those five patients target therapy with ATRA was initiated.

RT-PCR analysis also detected molecular abnormalities in the Core binding factor (CBF) in 10 AML patients; the presence of the AML/ETO1 fusion gene was confirmed in 3 patient and $\mathrm{CBF} \beta / \mathrm{MYH} 11$ in 7 patients.

Molecular analyses enabled $23.7 \%$ of the cases from our study to be classified in the adequate genetic entities of AML with different prognosis requiring different therapeutic approach.

\subsection{Results from the analyses of the clinical data of the patients}

We evaluate the distributions of the patients from our study group in the different grades of the Eastern Cooperative Oncology Group (EKOG) performance status scale (Oken et al. 1982)(Figure 6). All the patients with EKOG performance status higher than grade 2 and patients with serious co morbidities were not suitable candidates for alloSCT.

Furthermore, all the obtained results were correlated and consecutively effective treatment strategy for each single acute leukemia patient was selected.

\section{Discussion}

Modern diagnostic approach for acute leukemias combines cytomorphology, cytochemistry, multiparameter flow cytometry, chromosome banding analysis, accompanied by diverse fluorescence in situ hybridization techniques, and molecular analyses. The correct diagnosis is essential for classification of this heterogeneous complex of disorders and plays a central role for individual risk stratification and therapeutic decisions (Haferlach et al., 2007; Lichtman et al., 2010)

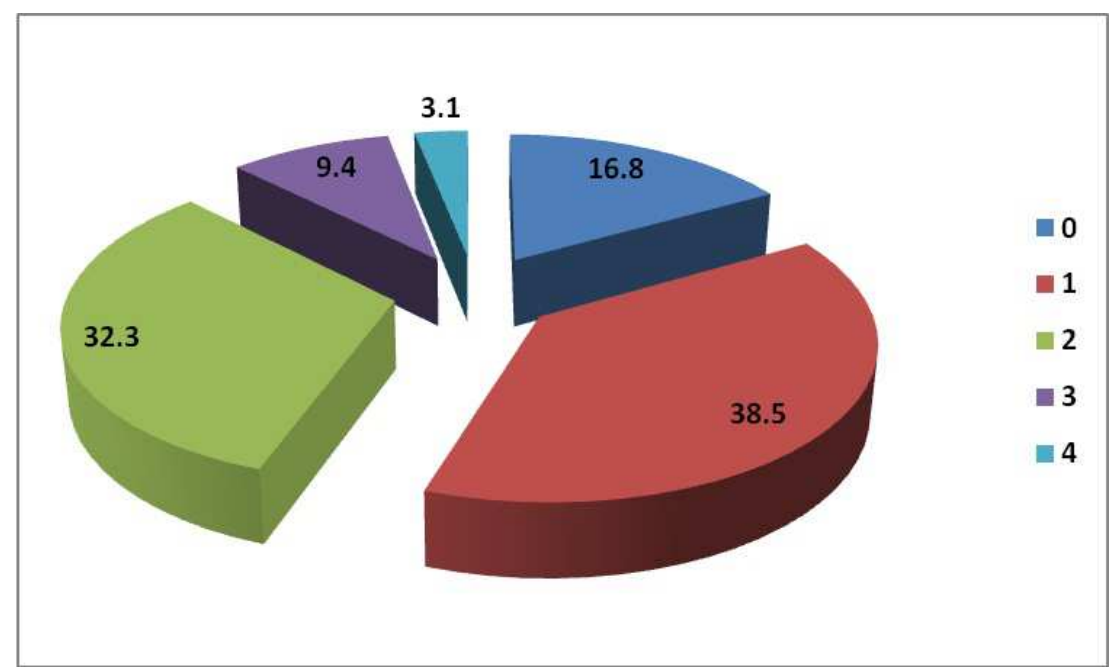

Fig. 6. Distribution of patients according to the grades of the EKOG performance status 


\subsection{Immunophenotyping in modern diagnosis of AML}

Assignment of lineage is critical in the diagnostic evaluation of acute leukemia, as treatment for AML and ALL markedly differs. Myeloid and lymphoid lineage may be distinguished based on cellular morphology, cytochemical staining, and expression of lineage-specific antigens (Döhner et al., 2010). Analyses of diagnostic evaluation of acute leukemia in our study showed that immunophenotyping was necessary for lineage assignment in $4(8.9 \%)$ cases that were morphologically and cytochemically undifferentiated, and also for correction of the lineage that was assigned based on morphology and cytochemistry in $3(3.8 \%)$ additional cases.

Flow cytometric immunophenotyping is a powerful technological tool that aids in the diagnosis, classification and monitoring of hematological malignancies. It is essential in the diagnosis of AML, as it demonstrates a particular lineage involvement and has a prognostic significance in the majority of AML cases. We used the panel based on the recommendation of the EGIL group and BTSH. Our analyses comprised of a two step process with the first panel of markers being applied to all cases of acute leukemia and the second only in patients with AML that did not demonstrate a clear myeloid commitment. We also evaluated further lymphoid antigen positive AML cases by using the second panel of McAb (Stelzer \& Goodpasture, 2000).

The second panel of McAb was aimed at identifying uncommon types of AML, such as those with megakaryocytic or elytroid differentiation and the exclusion or conformation of diagnosis of non-hematological malignancy. In our study, we applied the second AML panel in 27 cases; 4 which did not demonstrate clear myeloid commitment and 23 cases with lymphoid antigen positive AML cases. With our primary McAb we were able to differentiate AML form ALL in 96.8\% of cases. Only in one patient (AML-M6-1.5\%) lineage differentiation was assigned after staining with the secondary McAB panel and one case of non-hematological malignancy was confirmed.

Immunophenotyping was crucial in all cases of poorly differentiated myeloid leukemia (AML-M0), megakaryoblatstic leukemia (AML-M7) and in some case of monoblastic leukemia (AML-M5) and those with primitive erythroid cells as predominant leukemic cells (AML-M6). This is also important for recognizing an AML case that co-expresses lymphoidassociated antigens. In addition, immunophenotyping enables recognition of unusual forms of acute leukemia: designated acute biphenotypic or acute mixed lineage leukemia. The leukemia associated immunophenotype (LAIP) of the blast cells is a useful tool for detection of minimal residual disease in AML cases (Döhner et al., 2010; Stelzer \& Goodpasture, 2000; Swerdlow et al., 2008).

In order to classify AML cases in the different AML entities we correlated the immunological data from immunophenotyping with the FAB morphological and cytochemical classification. One of the difficulties in knotting the flow cytometric data with traditional morphology is the lack of routine flow cytometric data analyses that would ensure correlation of the immunophenotyping data to abnormal morphologic counterpart. Our approach was based on the fact that complete eight-part differential of the myeloid lineage in the normal bone marrow could be done with correlations of the expression of CD45 expression versus light side scatter (SSC) characteristics of the cells. Extension of this technique to the analyses of leukemias allows abnormal cell to be recognized as independent clusters in CD45/SSC histograms with pattern of CD45 and SSC expression that correlate to the same pattern of the morphologically similar cells in normal bone marrow. Flow-cytometric analyses by using CD45 gating strategy reveled that leukemic 
myeloblasts demonstrate very similar CD45/SSC characteristics to normal myeloblasts, especially the early myeloblasts. In fact, leukemic cells generally demonstrate CD45/SSC characteristics that closely resemble their nearest normal morphological counterparts in the bone marrow. In the histograms the leukemic cells can be easily recognized as an abnormal cluster of cells in CD45/SSC "space" which is usually occupied by normal myeloid blasts. Using this method we define in our study group each category of AML as defined by FAB system (Stelzer \& Goodpasture, 2000). Early myeloblasts are presented at Figure 6. Flow cytometric analyses show that those leukemic cells demonstrate low light forward and side scatter (FSC\&SSC), which means that those cells are small and don't contain any granules. They also have low CD45 expression.

The predominant immunophenotype characteristics of early myeloblasts are an expression of all pan-myeloid antigens: CD13, CD33, CD117 and HLA-DR and lack expression of more mature myeloid antigens such as CD15 and CD14. Also, high proportion of the leukemic cells expresses CD34. With the maturation process of the blast cells, CD34 expression becomes more heterogeneous and weaker. The densest is at AML-M0 blasts, which typically express only one myeloid-associated antigen plus. Myeloid blasts that arise as a result of the genetic change in more mature myeloid progenitor lose the characteristics of the early myeloblasts. For example, AML-M3 blasts usually lack the expression of CD34 and HLADR.

At Figure 7 are presents more mature myeloblasts, M5 blast. It is obvious that they are bigger when compared with the AML-M1 blasts presented on Figure 6, and contain some more granules (have higher FSC\&SSC). Immunophenotypically, they are characterized with expression of some more mature myeloid markers as CD14 and CD15, and in most of the case with lost CD34 expression.

The results from our study showed that routine immunophenotyping improved the diagnosis in $12(15,5 \%)$ cases with acute leukemia which was essential for more appropriate individual clinical stratification of the patient with acute leukemia. Our data demonstrate that flow cytometry in correlation with the morphological classification criteria for each subtype of AML can be used for initial classification of each FAB AML entities and and justify routine implementation of flow cytometry analyses in the diagnostic evaluation of AML cases.

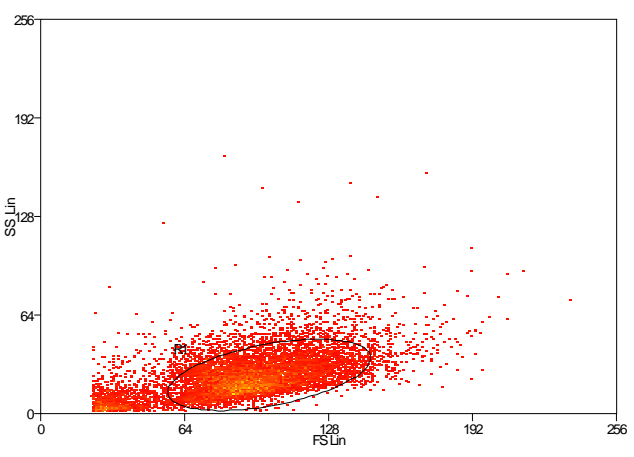

A

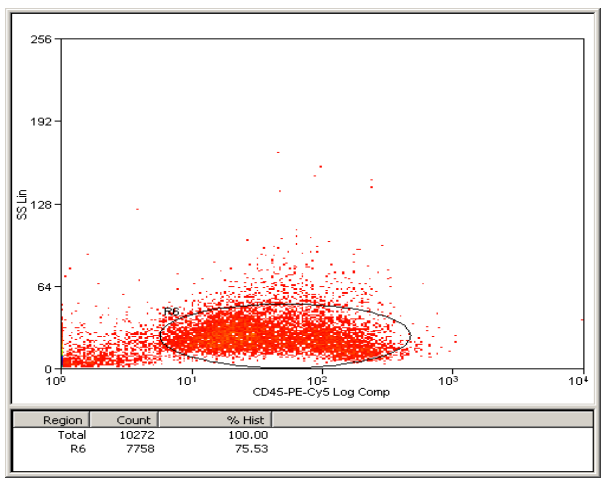

B

Fig. 6. Histogram analyses of early M1 myeloblasts ; A: Blast cells demonostrate low FSC\&SSC, B:Blast cells have low CD45 expression 


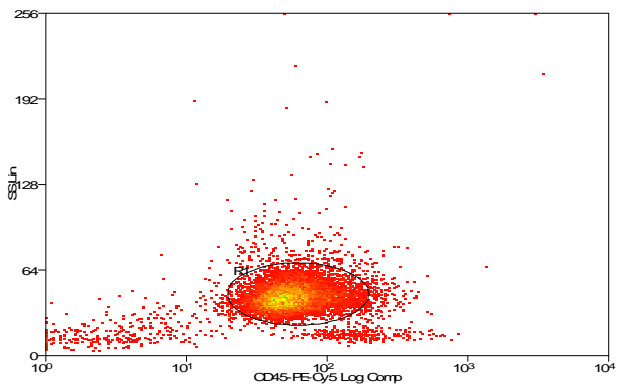

A

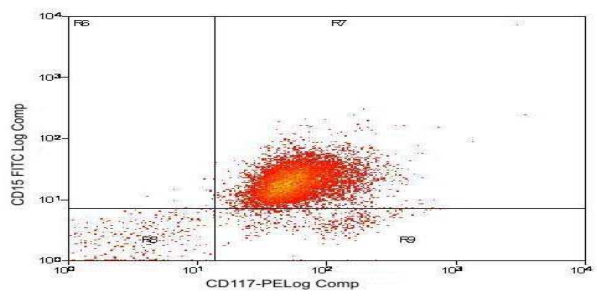

B

Fig. 7. Histogram analyses of M5-myloblasts; A: Blast cells are biger and more granular and have higher CD45,B: Blasts cells express CD117 and the myeloid expression maturation marker CD15

\subsection{Molecular analyses in the modern diagnosis of AML}

Results from the immunophenotying guided us to perform exact molecular analyses and further define some specific genetic entities of AML. We tested our AML patients for the presence of PML/RAR $\alpha$, AML1/ETO and CBF $\beta /$ MYH11 fusion transcripts, by using RTPCR method. Results from those analyses additionally improved the exact classification of the AML subtypes and made target and specific therapy available for some of the specific AML subtypes (Marcucci et al., 2000; Perea et al.2006; Wang et al., 2008)

Nonrandom chromosomal abnormalities are identified at the cytogenetic level in approximately $55 \%$ of all adult primary or de novo AML patients and have long been recognized as important independent prognostic indicators for achievement of complete remission $(\mathrm{CR})$, duration of first $\mathrm{CR}$, and survival after intensive chemotherapy treatment. Two of the most prevalent cytogenetic subtypes of adult primary or de novo AML are $t$ (8; 21) (q22; q22) and inv (16) (p13q22). These abnormalities result in the disruption of genes encoding subunits of the CBF, which is a $\alpha \beta$ heterodimeric transcriptional factor involved in the regulation of normal hematopoiesis and are collectively referred as CBF-AML. At the molecular level, $\mathrm{t}(8 ; 21)(\mathrm{q} 22 ; \mathrm{q} 22)$ and inv(16)(p13q22) result in the creation of novel fusion genes, AML1/ETO and CBF $\beta /$ MYH11. Detection of $t(8 ; 21)(q 22 ; q 22)$ or inv(16)(p13q22) in adult patients with primary AML is a favorable independent prognostic indicator for achievement of cure after intensive chemotherapy or bone marrow transplantation, and may serve as a as a paradigm of the risk-adapted treatment in AML (Döhner et al. 2010\& Marcucci et al., 2000).

In almost all studies of adult primary AML, the highest CR rate (approximately $90 \%$ ) and the longest disease free survival (DFS) at 5 years (approximately $50 \%$ ) have been associated with CBF-AML cases. It has been suggested that the superior outcome of AML patients with $\mathrm{CBF}$ gene rearrangements compared with other AML patients may be attributed to an increased sensitivity of the leukemic blasts to cytarabine that in combination with anthracyclines represents the backbone of AML treatment. The collective analysis of all data regarding the treatment of CBF-AML indicates that incorporation of multiple courses of high dose of cytarabine as consolidation therapy should be considered as the therapeutic standard for primary adult CBF-AML (Marcucci et al., 2001; Perea et al.2006). 
The prognostic impact of the CBF gene rearrangements appears equally significant in the setting of BMT of AML patients in first CR. However, the iatrogenic morbidity and mortality of BMT suggest that patients with CBF-AML should not receive this therapeutic modality as initial treatment. The collective analysis of all data regarding the implementation of all SCT in AML treatment suggest that although allo SCT and auto SCT may have a potential role in the initial management of AML other than CBF-AML, the treatment-related morbidity and mortality of SCT represent a therapeutic limitation for treatment of CBF-AML patients. Considering the high probability of cure that these patients can achieve with intensive chemotherapy, it is reasonable to spare them the toxicity of SCT as consolidation in first complete remission (Löwenberg et al., 2008a; Koreth et al, 2009; Marcucci et al., 2000; Marcucci et al., 2001 \& Perea et al.2006).

APL or AML-M3 is a distinct subtype of AML which is characterized by a $t(15 ; 17)$ translocation leading to a PML-RARA fusion gene. Historically, recognition of this form of AML as a separate entity was important for the clinicians, not because the chemotherapy used as treatment differed substantially from that used for the other subtypes of AML, but because the relatively common occurrence of life-threatening coagulopathy mandated special supportive maneuvers, including the use of low-dose heparin and aggressive blood product support. In the past, induction mortality was often significant, with some older series reporting an incidence approaching 50\%. APL was typified with the worst features associated with leukemia: a fulminant disorder that struck primarily young people, had devastating effects on an individual's life, and resulted in death for a large number of patients during the initial phases of treatment. The last two decades have seen a fundamental shift from this paradigm, with APL now recognized as one of the most curable forms of acute leukemia. Introduction of the differentiation therapy with ATRA into the treatment of APL completely revolutionized the management and outcome of this disease, and presents the first model of targeted therapy for cancer. This agent represents one of the most spectacular advances in the treatment of human cancer, providing the first paradigm of molecularly targeted treatment. Treatment of APL with ATRA combined with anthracycline-based chemotherapy yields a CR rate of approximately $90 \%$ for newly diagnosed APLs. The relapse rate is approximately $20 \%$, and with the development of new molecular target therapies such as arsenic trioxide, a cure can now be expected even for relapsed patients. After the advent of ATRA, the introduction of arsenic trioxide (ATO), probably the most biologically active single drug in APL has provided a valuable addition to the armamentarium and may have contributed to further improvements in the clinical outcome of this disease. Several treatment strategies using these agents, usually in combination with chemotherapy, have provided excellent therapeutic results with survival rates exceeding $70 \%$ in multicenter clinical trials. Cure of patients with APL depends not only on the effective use of combination therapy involving differentiating and classical cytotoxic agents, but also, critically, upon supportive care measures that take into particular account the biology of the disease and the complications associated with molecularly targeted therapies. Moreover, it is important to consider diagnostic suspicion of APL as a medical emergency (uncommon in AML) that requires several specific and simultaneous actions, including immediate commencement of ATRA therapy, prompt genetic diagnosis, and measures to counteract the coagulopathy (Grimwade et al., 2002; Wang et al., 2008). 


\subsubsection{Why we used RT-PCR method for detection of the genetic abnormalities?}

RT-PCR methods for detecting the PML/RAR $\alpha$ fusion transcript also provide the "gold standard" approach for confirming a diagnosis of APL. In addition to its high specificity and sensitivity, it is essential for defining PML breakpoint location thereby establishing the target for reliable monitoring of the minimal residual disease (MRD).

Standard cytogenetic analysis is currently the most common method for identifying the most common recurrent cytogenetic abnormalities $t(8 ; 21)(q 22 ; q 22)$ and $\operatorname{inv}(16)(p 13 q 22)$ or $\mathrm{t}(16 ; 16)(\mathrm{p} 13 ; \mathrm{q} 22)$ in AML patients. This technique also allows detection of secondary chromosomal abnormalities such as del $(9 q),-X$ and $-Y$ which are frequently associated with $t(8 ; 21)(q 22 ; q 22)$, or +8 and +22 more often found with inv(16)(p13q22). Still, despite the recent improvements in the cytogenetic methodology and the use of complementary techniques such as fluorescence in situ hybridization and comparative genomic hybridization to increase the rate of successful karyotyping, the possibility that subtle structural chromosomal aberrations are missed remains (Marcucci et al., 2000). In $t(8 ; 21)$ (q22;q22) or inv(16) (p13q22), failure to detect submicroscopic (cryptic) rearrangements of the involved genes leads to false-negative results that may ultimately impact the correct stratification of this patient population in prognostic and risk-adapted therapy groups. Sensitive molecular methodologies such as RT-PCR have been successfully used to detect cryptic CBF abnormalities in diagnostic samples of AML patients with karyotypes that are otherwise negative for $\mathrm{t}(8 ; 21)(\mathrm{q} 22 ; \mathrm{q} 22)$ or inv(16)(p13q22). Andrieu et al.,1997 reported detection of AML1/ETO fusion transcripts by RT-PCR in cases with unsuccessful cytogenetic studies, normal karyotypes, or karyotypes other than $t(8: 21)(q 22 ; q 22)$ such as $\operatorname{del}(8 q), i(8)(q 10)$ or del(9q). Langabeer et al., 1997 used a two-step RT-PCR to screen for the AMLI/ETO and CBF $\beta /$ MYHll fusion transcripts in AML patients entered into the U.K. MRC AML 10, 11, and 12 trials and compared the results with conventional cytogenetics. All patients with cytogenetic evidence of $\mathrm{t}(8 ; 21)(\mathrm{q} 22 ; \mathrm{q} 22)$ or $\operatorname{inv}(16)(\mathrm{pl} 3 \mathrm{q} 22)$ were positive by RT-PCR for the corresponding fusion transcripts. RT-PCR was also positive in 31 cases (19 cases of AML1/ETO and 12 cases of CBF $\beta /$ MYH11) without CBF cytogenetic abnormalities, increasing the overall detection rate of " $\mathrm{t}(8 ; 21)(\mathrm{q} 22 ; \mathrm{q} 22)$ " and "inv(16)(p13q22)" from $8.1 \%$ to $12.9 \%$ and from $6.5 \%$ to $10.3 \%$, respectively. The authors of these studies concluded that all primary AML should be routinely tested for the presence of the CBF fusion genes by molecular screening to improve genomic stratification of AML patients in risk-related treatment groups (Marcucci et al., 2000).

Although patients with CBF-AML have a relatively good prognosis, a substantial number of them relapse and eventually die of their disease. Because relapse after intensive treatment is likely to occur as the result of failure to completely eradicate the leukemic blasts, evaluation of MRD by a sensitive molecular technique such as PCR based techniques has been proposed to detect persistence of malignant clones and predict disease relapse in AML patients in CR. This strategy has been successful in CML (Radich et al.,1995) and acute promyelocytic leukemia (Grimwade et al., 2002; Wang et al., 2008), but its clinical applicability to other subgroups of acute leukemia remains controversial.

RQ-PCR provides the most sensitive parameters for AML with reciprocal gene fusions PML/RAR $\alpha$, CBF $\beta-M Y H 11$, AML1-ETO (Haferlach et al., 2007). The score of gene expression of the respective fusion transcripts after consolidation therapy in relation to gene expression at diagnosis correlates significantly with prognosis [Haferlach et al., 2007]. The 
prognostic value of quantitative PCR in MRD diagnostics in these subgroups was demonstrated in several studies. Patients with an MRD level<1\% after induction chemotherapy in relation to initial diagnosis had a relapse rate of $8 \%$ in contrast to $91 \%$ in the patients with MRD levels of $\geq 1 \%$ in the investigation on the CBF-leukemias by Krauter et al.,2003. Marcucci et al, 2000, were able to define a distinct transcript copy number in inv(16)/CBFB/ MYH11 below which relapse was unlikely and above which relapse occurred with high probability. A Gruppo Italiano Malattie Ematologiche Maligne dell' Adulto (GIMEMA) trial showed that molecular switch from CR to PML/RAR $\alpha$ positivity was followed by hematologic relapse after a median time of 3 months in 95\% of all APL cases (Diverio et al. 1998). Data from different studies indicate that of all AML subtypes, quantitative PCR monitoring could be best established for the reciprocal gene fusions.

Molecular analyses enabled $23.7 \%$ of the cases of our study to be classified in the adequate genetic entities of AML with different prognosis requiring different therapeutically approach.

\subsection{Analyses of the clinical characteristics of the patients in the era of modern diagnosis of AML 5.3.1 Analyses of the EKOG performance status}

Several studies support the use of the ECOG performance status as a measure of physical functioning and prognosis in patients with AML (Oken et al. 1982). A retrospective study of data from five Southwestern Oncology Group (SWOG) trials that included 968 patients with AML found that the mortality rate within 30 days of initiation of induction therapy is dependent upon both the patient's age and ECOG performance status at diagnosis. A second retrospective analysis of 998 patients age 65 or greater (range 65 to 89; median 71 years) who underwent intensive induction chemotherapy reported eight-week mortality rates of 23, 40, and 72 percent for patients with ECOG PS of zero to 1, 2, and 3 to 4, respectively. One-year overall survival rates for the same groups were 35, 25, and 7 percent, respectively. A third retrospective study of 2767 patients with non-APL AML from the Swedish acute leukemia registry also reported that older patients with an ECOG PS of zero to 1 had 30 day death rates after intensive chemotherapy of less than 15 percent, while patients with a PS of 3 or 4 had higher early death rates regardless of patient age ranging from 26 to 36 percent. Seventy percent of patients up to age 80 years had a PS of zero to 2 . A prospective trial of induction chemotherapy with cytarabine plus daunorubicin in 811 older adults (median age 67 years, range 60 to 83 years) with ECOG PS of zero to 2 reported a 30day mortality rate of 11 percent (Appelbaum et al, 2006). We used the EKOG performance status score in initial randomization of our AML patients for different induction and consolidation approaches, in order to avoid intensive induction and consolidation treatment for patient with EKOG performance status higher than 2. Only $8(12.5 \%)$ patients from our study group have EKOG performance status higher than 2, but only 3 of those patients were younger than 60 years of age.

\subsubsection{Analyses of the comorbidities}

Comorbidity is an also a distinct additional clinical entity that exists or may occur during the clinical course of patient with a primary disease (i.e. AML). Comorbid conditions are poor prognostic factors especially in older patients with AML. Patients with age-related 
chronic cardiac, pulmonary, hepatic or renal disorders or diabetes suffer greater acute toxicity from chemotherapy. Older patients may also have decreased bone marrow regenerative capacity, even after successful leukemia cytoreduction. Inability to tolerate long periods of pancytopenia and malnutrition or the nephrotoxicity of drugs such as amino glycosides or amphotericin remains a major barrier to successful treatment (Piccirillo et al.2004; Sorror et al, 2005). Six 6(9,3\%) patients from our study had seriouos comorbidities which limited the aplication of intensive chemotherapy in their treatment. Five of them were older than 60years.

\subsection{Approach to AML diagnostic algorithms}

Modern diagnostic approaches in the AML should be created as integral and basic parts of optimized treatment concepts for the benefit of the each individual patient. The ultimate test of any disease diagnostic algorithm approach is its usefulness in guiding the selection of effective treatment strategies. Algorithms that provide a basis for risk-adapted therapeutic choices may include immunological markers, cytogenetic factors, molecular markers as well as clinical parameters (e.g., age, attainment of an early or late complete remission) and hematological determinants (e.g., secondary AML, white blood cell count at diagnosis) (Haferlach et al., 2007).

A comprehensive approach in diagnosis, classification, and treatment follow-up in patients with acute leukemias can, therefore, be suggested by diagnostic algorithms, which also show the relationship and the hierarchy between single methods. These standard guidelines for AML mostly result from a combination of different methods and intend to add prognostic information (Lowenberg 2008).

Our diagnostic algorithm for AML (as shown in Fig. 8) starts with cytomorphology and cytochemistry. These methods should be performed in combination: cytomorphology and cytochemistry allow rapid classification of the acute leukemias and further enables the choice of the antibody panel for flow cytometric analyses. In case cytomorphology gives indices for characteristic aberrations - in the FAB subtypes M3/M3v for $t(15 ; 17) / \mathrm{PML} /$ RAR $\alpha$, in FAB M4eo for inv(16)/CBF $\beta / M Y H 11$, or in $\mathrm{M} 1 / 2$ with the characteristic long Auer rods for the $t(8 ; 21) /$ AML1/ETO, PCR analyses for these rearrangements should be promptly applied.

Especially in case of suspicion for APL due to clinical symptoms or due to the morphological findings, RT-PCR for PML/RAR $\alpha$ should be initiated as soon as possible (Schoch et al., 2002). We think that, regardless of the morphological, cytochemical and immunological futures of the blast cells, RT-PCR for the fusion oncogene PML/RAR $\alpha$ are recommendable in all AML cases. The RT- PCR method is the most sensitive and rapid technique for detection of this oncogene and provides an optimal basis for MRD analyses. Further we suggest all AML cases which are PML/RAR $\alpha$ negative to be tested for the presence of the reciprocal fusions genes that describe CBF-AML, AML1/ETO and $\mathrm{CBF} \beta / \mathrm{MYH11}$.Those analyses provides the basis for sub-classification of the AML cases in prognostically relevant subclasses. This is the prerequisite for adequate individual clinical risk stratification and therapeutic decisions.

Moreover, we correlated the obtained result for the applied multimodal diagnostic approach with the patient age, EKOG performance status and comorbidities, which allowed us to optimize the individual risk stratification for each AML patient. 


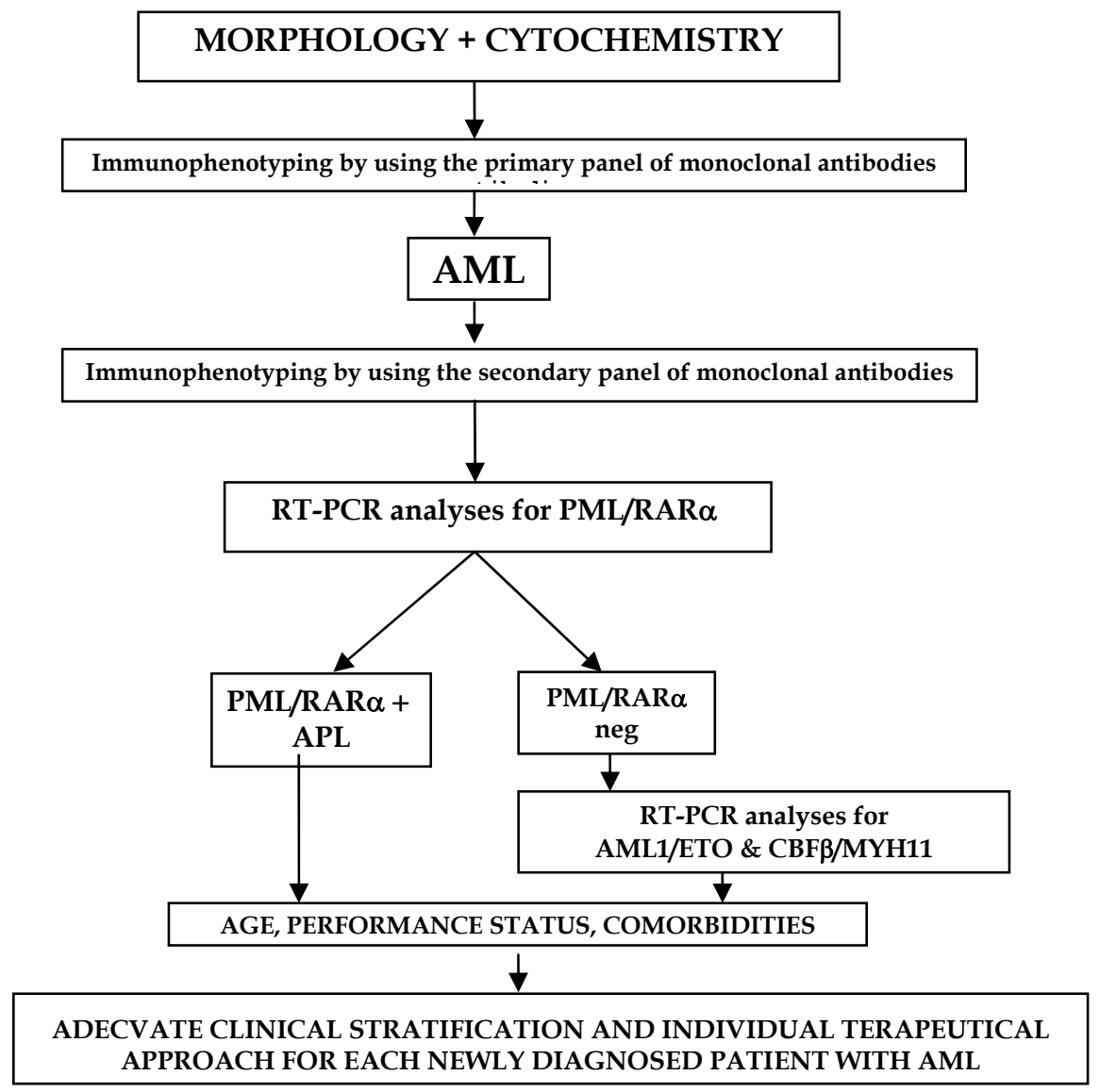

Fig. 8. Diagnostic algorithm and algorithm for risk adapted therapy in AML patients

\section{Conclusions}

A basis for every therapeutic decision in AML cases should be provided by a multimodal diagnostic approach. The optimal therapeutic conditions are based on exact classification and prognosis of the AML subtype at diagnosis and to delineation of sensitive markers for MRD studies during the complete hematologic remission. MRD methods have many potential applications in the clinical management of patients with acute leukemia. Today, a multimodal diagnostic approach which combines different diagnostic techniques is needed to meet these requirements. The diagnostic process is becoming more demanding with respect to experience, time and costs due to the expansion of methods and algorithms, which guide the diagnostic procedure from basic to more specific methods and which finally lead to results that are essential for modern diagnostics and therapeutic concepts. There are numerous overlaps between different diagnostic methods. These can be used for optimal pathways in the complex diagnostic proceedings and for validation of the results of single methods, which can be summarized in diagnostic algorithms. Basic morphological 
and cytochemical analyses performed in our study group established the lineage assignment of the blasts cells in $68(88.3 \%)$ patients. Routine immunophenotyping improved the diagnosis in 12 (15.5\%) more cases. Molecular analyses enabled $23.7 \%$ of the cases from our study to be classified in the adequate genetic entities of AML with different prognosis requiring different therapeutical approach.

The applied multimodal diagnostic approach consisted of minimal number of cytomorphological, cytochemistry, immunological and molecular analyses enables improved and more precise diagnosis and clinical stratification in 38.2\% acute leukemia patients from our study. Moreover, when we correlate those results with the results obtained from the analyses of the EKOG performance status and the incidence of the serious comborbidities in our study group, an additional $12.5 \%$ of the patients were stratified to a different risk adapted therapy.

Our initial results are consistent with literature data and indicate that our applied multimodal diagnostic approach improved the diagnosis of the specific genetic entities of AML in which specific treatment approach is indicated and allows individual clinical stratification in treatment protocols of the patients.

\section{References}

Andrieu, V., Radford-Weiss, I., Troussard, X., Chane, C., Valensi, F., Guesnu, M., Haddad, E., Viguier, F., Dreyfus, F.; Varet, B.; Flandrin, G.; \& Macintyre, E. (1997). Molecular detection of $\mathrm{t}(8 ; 2 \mathrm{I}) /$ AMLI-ETO in AML MI/M2: Correlation with cytogenetics, morphology and immunophenotype. Br J Haematol, Vol.4, No.92,(March 1996), pp. 855-865, ISSN 0007-1048

Appelbaum, F.R., Rowe, J.M., Radich, J., \& Dick, J.E. (2001). Acute myeloid leukemia. Hematology (Am Soc Hematol Educ Program),(November 2001), pp. 62-86, ISSN 1520-4391

Appelbaum, F.R., Gundacker, H., Head, D.R., Slovak, M.L., Willman, C.L., Godwin, J.E., Anderson, J.E.,\& Petersdorf, S.H. (2006). Age and acute myeloid leukemia. Blood,Vol. 107, No.9, (May 2006), pp.3481-3485,ISSN0006-4971

Armitage P., Berry G., \& Matthews J.N.S.(2002) Statistical Methods in Medical Research (4th edition),Blackwell ISBN:978063052578,Oxford,UKBain, BJ, Barnet, D, Linch, D, Matutes, E, \& Reilly, J.T. (2002).Revised guidelines on immunophenotyping in acute leukemias and chronic lymphoproliferative disorders. Clin Lab Hem, Vol. 24,(2002),pp.1-13, ISSN 0141-9854

Beillard, E., Pallisgaard, N., van der Velden, V.H., Bi, W., Dee, R., van der Schoot E., Delabesse E., Macintyre E., Gottardi E., Saglio G., Watzinger F., Lion T., van Dongen, J.J., Hokland, P., \& Gabert, J.(2003). Evaluation of candidate control genes for diagnosis and residual disease detection in leukemic patients using 'real-time' quantitative reversetranscriptase polymerase chain reaction (RQ-PCR) - a Europe against cancer program. Leukemia, Vol. 17, No. 12,( December 2003), pp 2474-2486, ISSN 0887-6924

Bene, M.C., Castoldi, G., Knapp, W., Ludwig, W.D., Matutes, E., Orfao, A., \& van't Veer, M.B. (1995). Proposals for the immunological classification of acute leukemias. European Group for the Immunological Characterization of Leukemias (EGIL). Leukemia, Vol. 9, No. 10, (October 1995), pp.1783-1786, ISSN 0887-6924

Bennett, J.M., Catovsky, D., Daniel, M.T., Flandrin, G., Galton, D.A., Gralnick, H.R., \& Sultan, C.(1976). Proposals for the classification of the acute leukaemias. FrenchAmerican-British (FAB) Cooperative Group. Br J Haematol,Vol.33, No.4 (August 1976), pp.451-458, ISSN 0007-1048 
Borowitz, M.I., Guenter, K.I., Shults, K.E., \& Stelzer, G.T. (1993). Immunophenotyping of acute leukemia by flow cytometry analysis. Use of CD45 and right-angle light scatter to gate on leukaemic blasts in three colour analysis. Am J Clin Pathol, No.100,(November 1993), pp.534-540,ISSN 0002-9173

Byrd, J.C., Mrózek, K., Dodge, R.K., Carroll, A.J., Edwards, C.G., Arthur, D.C., Pettenati, M.J., Patil, S.R., Rao, K.W., Watson, M.S., Koduru, P.R., Moore, J.O., Stone, R.M., Mayer, R.J., Feldman, E.J., Davey, F.R., Schiffer, C.A., Larson, R.A., \& Bloomfield, C.D.; Cancer and Leukemia Group B (CALGB 8461). (2002). Pretreatment cytogenetic abnormalities are predictive of induction success, cumulative incidence of relapse, and overall survival in adult patients with de novo acute myeloid leukemia: results from Cancer and Leukemia Group B (CALGB 8461).Blood, Vol. 100, No.13, (December 2002), pp. 4325-4336, ISSN 0006-4971

Cornelissen, J.J., van Putten, W.L., Verdonck, L.F., Theobald, M., Jacky E., Daenen, S.M., van Marwijk-Kooy, M., Wijermans, P., Schouten, H., Huijgens, P.C., van der Lelie, H., Fey, M., Ferrant, A., Maertens, J., Gratwohl, A.,\& Lowenberg, B. (2007). Results of a HOVON-SAKK donor versus donor analysis of myeloablative HLA-identical sibling stem cell transplantation in first remission acute myeloid leukemia in young and middle aged adults: benefits for whom? Blood, Vol.109, No. 9, (May 2007), pp. 3658-3666,ISSN 0006-4971

Diverio D., Rossi V., Avvisati G., De Santis S., Pistilli A., Pane F., Saglio G., Martinelli G., Petti M.C., Santoro A., Pelicci, P.G., Mandelli, F., Biondi, A., \& Lo Coco, F.(1998). Early detection of relapse by prospective reverse transcriptase-polymerase chain reaction analysis of the PML/RAR alpha fusion gene in patients with acute promyelocytic leukemia enrolled in the GIMEMA-AIEOP multicenter "AIDA" trial. GIMEMA-AIEOP Multicenter "AIDA" Trial. Blood, Vol. 92, No.3, (August 1998), pp.784-789, ISSN 0006-4971

Döhner, H., Estey, E.H., Amadori, S., Appelbaum, F.R., Büchner, T., Burnett, A.K., Dombret, H., Fenaux, P., Grimwade, D., Larson, R.A., Lo-Coco, F., Naoe, T., Niederwieser, D., Ossenkoppele, G.J., Sanz, M.A., Sierra, J., Tallman, M.S., Löwenberg, B.,\& Bloomfield, C.D.; European Leukemia Net. (2010). Diagnosis and management of acute myeloid leukemia in adults: recommendations from an international expert panel, on behalf of the European Leukemia Net. Blood, Vol.115, No.3, (January 2010), pp.453-474, ISSN 0006-4971

Fernandez, H.F. (2010). New Trends in the Standard of Care for Initial Therapy of Acute Myeloid Leukemia. Hematology (Am Soc Hematol Educ Program), (November 2010), pp. 62-86, ISSN 1520-4391

First MIC Cooperative Study Group. (1986). Morphologic, immunologic, and cytogenetic (MIC) working classification of acute lymphoblastic leukemias: report of the workshop held in Leuven, Belgium, April 22-23, 1985. Cancer Genet Cytogenet, Vol. 23, No.3, (November 1986), pp.189-197, ISSN 0165-4608

Freeman, S.D., Jovanovic, J.V., \& Grimwade, D. (2008). Development of minimal residual disease-directed therapy in acute myeloid leukemia. Semin Oncol, Vol. 34, No.4, (August 2008), pp.388-400, ISSN 0093-7754

Gabert, J., Beillard, E., van der Velden, V.H., Bi, W., Grimwade, D., Pallisgaard, N., Barbany, G., Cazzaniga, G., Cayuela, J.M., Cavé, H., Pane, F., Aerts, J.L., De Micheli, D., Thirion, X., Pradel, V., González, M., Viehmann, S., Malec, M., Saglio, G., \& van Dongen, J.J. (2003). Standardization and quality control studies of 'real-time' quantitative reverse transcriptase polymerase chain reaction of fusion gene 
transcripts for residual disease detection in leukemia - A Europe Against Cancer Program. Leukemia, Vol.17, No.12, (December 2003), pp.2318-2357, ISSN 0887-6924

Grimwade, D. (2001). The clinical significance of cytogenetic abnormalities in acute myeloid leukaemia. Best Pract Res Clin Haematol, Vol. 14, No. 3, (September 2001), pp. $497-$ 529, ISSN 1521-6926

Grimwade, D. \& Lo Coco, F. (2002). Acute promyelocytic leukemia: a model for the role of molecular diagnosis and residual disease monitoring in directing treatment approach in acute myeloid leukemia. Leukemia, Vol.16, No.10,( October 2002), pp:.1959-1973, ISSN 0887-6924

Haferlach, T., Bacher, U., Kern, W., Schnittger, S., \& Haferlach, C. (2007). Diagnostic pathways in acute leukemias: a proposal for a multimodal approach. Ann Hematol, Vol. 86, No. 5, (May 2007), pp.311-327, ISSN 0939-5555

Haferlach, T. (2008). Molecular Genetic Pathways as Therapeutic Targets in Acute Myeloid Leukemia. Hematology (Am Soc Hematol Educ Program),(November 2008), pp.401411, ISSN 1520-4391

Koreth, J., Schlenk, R., Kopecky, K.J., Honda, S., Sierra, J., Djulbegovic, B.J., Wadleigh, M., De Angelo, D.J., Stone, R.M., Sakamaki, H., Appelbaum, F.R., Döhner, H., Antin, J.H., Soiffer, R.J.,\& Cutler, C. (2009). Allogeneic stem cell transplantation for acute myeloid leukemia in first complete remission: systematic review and meta-analysis of prospective clinical trials. JAMA, Vol. 301, No. 22, (June 2009), pp.2349-2361, ISSN 0098-7484.

Krauter, J., Gorlich, K., Ottmann, O., Lubbert, M., Dohner, H., Heit, W., Kanz, L., Ganser, A., \& Hei,l G. (2003). Prognostic value of minimal residual disease quantification by real-time reverse transcriptase polymerase chain reaction in patients with core binding factor leukemias. J Clin Oncol, Vol. 21, No.23, (December 2003), pp.44134422, ISSN 0002-9173

Langabeer, S.E., Walker, H., Rogers, J.R., Burnett, A.K., Wheatley, K., Swirsky, D., Goldstone, A.H., \& Linch, D.C. (1997). Incidence of AMLl/ETO fusion transcripts in patients entered into the MRC AML trials. Br J Haematol, Vol. 99, No. 4, (December 19970), pp.925-928, ISSN 0007-1048

Langabeer, S.E., Walker, H., Gale, R.E., Wheatley, K., Burnett, A.K., Goldstone, A.H., \& Linch, DC.(1997). Frequency of CBF $\beta /$ MYHII fusion transcripts in patients entered into the UK MRC AML trials. The MRC Adult Leukaemia Working Party.Br J Haematol, Vol. 96, No. 4, (March 1997), pp. 736-739, ISSN 0007-1048

Lichtman, M.A.; Kipps, T.J.; Seligsohn, U.; Kaushansky, K.; \& Prchal, J.T. (2010). Williams Hematology, Eighth Edition, The McGraw-Hill Companies, Inc., ISBN 978-0-07162144-1, China

Löwenberg, B. (2008a). Diagnosis and prognosis in acute myeloid leukemia: the art of distinction. N Engl J Med, Vol. 358, No. 18, (May 2008), pp. 1960-1962, ISSN 0028-4793

Löwenberg, B. (2008b). Acute Myeloid Leukemia: The Challenge of Capturing Disease Variety. Hematology (Am Soc Hematol Educ Program), (November 2008), pp.1-11, ISSN 1520-4391

Marcucci, G., Caligiuri, M.A., Döhner, H., Archer, K.J., Schlenk, R.F., Döhner, K., Maghraby, E.A., \& Bloomfield, C.D. (2001).Quantification of CBF beta/MYH11 fusion transcript by real time RT-PCR in patients with inv(16) acute myeloid leukemia. Leukemia, Vol. 15, No.7, (July 2001), pp. 1072-1080, ISSN 0887-6924

Marcucci, G., et al. (2000). Molecular and Clinical Advances in Core Binding Factor Primary Acute Myeloid Leukemia: A Paradigm for Translational Research in Malignant Hematology. Cancer Investigation, Vol.18, No. 8, (2000), pp.768-780, ISSN 0735-7907 
Oken, M.M., Creech, R.H., Tormey, D.C., Horton, J., Davis, T.E., McFadden, E.T., \& Carbone, P.P. (1982). Toxicity And Response Criteria Of The Eastern Cooperative Oncology Group. Am J Clin Oncol, Vol.5, No.6, (December 1982), pp.649-655, ISSN 0002-9173

Panovska-Stavridis, I., Cevreska, L., Trajkova, S., Hadzi-Pecova, L., Trajkov, D., Petlickovski, A., Srbinovska, O., Matevska, N., Dimovski, A., \& Spiroski, M. (2008). Preliminary results of introducing the method multiparameter flow cytometry in patients with acute leukemia in the Republic of Macedonia. Macedonian Journal of Medical Sciences, No.1(2), pp:36-43, ISSN 1857-5749

Perea, G., Lasa, A., Aventín, A., Domingo, A., Villamor, N., Queipo, de Llano, M.P., Llorente, A., Juncà, J., Palacios, C., Fernández, C., Gallart, M., Font, L., Tormo, M., Florensa, L., Bargay, J., Martí, J.M., Vivancos, P., Torres, P., Berlanga, J.J., Badell, I., Brunet, S., Sierra, J., \& Nomdedéu, J.F.; Grupo Cooperativo para el Estudio y Tratamiento de las Leucemias Agudas y Miel.(2006). Prognostic value of minimal residual disease (MRD) in acute myeloid leukemia (AML) with favorable cytogeneticst(8;21) and inv(16)]. Leukemia, Vol. 20, No.1, (January 2006), pp.87-94, ISSN 0887-6924

Piccirillo, J.F., Tierney, R.M., Costas, I., Grove, L., \& Spitznagel, E.L. Jr.(2004). Prognostic importance of comorbidity in a hospital-based cancer registry. JAMA, Vol. 291, No. 20, (May 2004), pp.2441-2447, ISSN 0098-7484

Radich, J.P., Gehly, G., Gooley, T., Bryant, E., Clift, R.A., Collins, S., Edmands, S., Kirk, J., Lee, A., Kessler, P., et al. (1995). Polymerase chain reaction detection of the BCRABL fusion transcript after allogeneic marrow transplantation for chronic myeloid leukemia: Results and implications in 346 patients. Blood, Vol. 85, No. 9, (May 1995), pp.2632-2638, ISSN 0006-4971

Schlenk, R.F., Döhner, K., Krauter, J., Fröhling, S., Corbacioglu, A., Bullinger, L., Habdank, M., Späth, D., Morgan, M., Benner, A., Schlegelberger, B., Heil, G., Ganser, A., \& Döhner, H.; German-Austrian Acute Myeloid Leukemia Study Group. (2008). Mutations and treatment outcome in cytogenetically normal acute myeloid leukemia. N Engl J Med. Vol. 358, No. 18, (May 2008), pp.1909-1918, ISSN 0028-4793

Schoch, C., Schnittger, S., Kern, W., Lengfelder, E., Löffler, H., Hiddemann, W., \& Haferlach, T. (2002). Rapid diagnostic approach to PML-RAR alpha-positive acute promyelocytic leukemia. Hematol J ,Vol.3, No.5, (2002), pp.259-263, ISSN 1466-4860

Sorror, M.L., Maris, M.B., Storb, R., Baron, F., Sandmaier, B.M., Maloney, D.G., Storer, B.(2005). Hematopoietic cell transplantation (HCT)-specific comorbidity index: a new tool for risk assessment before allogeneic HCT. Blood. Vol. 106, No.8, (October 2005), pp.2912-2919, ISSN 0006-4971

Stelzer, G.T., \& Goodpasture, L. (2000). Use of multiparameter flow cytometry and immunophenotyping for the diagnosis and classification of acute myeloid leukemia, In Immunophenotyping, Stewarat C,S \& Nicholson J.K.A.,pp.215238,Wiley-Liss, ISBN 0-471-23957-7, United States of America

Swerdlow, S.H.; Campo, E.; Harris, N.L.; Jaffe, E.S.; Pileri, S.A.; Stein, H.; Thiele, J.; Vardiman, J.W. (2008). WHO Classification of Tumours of Haematopoietic and Lymphoid Tissues, Fourth Edition, IARC, WHO Press, ISBN 9789283224310, Geneva, Switzerland

Vardiman, J.W., Thiele, J., Arber, D.A., Brunning, R.D., Borowitz, M.J., Porwit, A., Harris, N.L., Le Beau, M.M., Hellström-Lindberg, E., Tefferi, A., \& Bloomfield, C.D.(2009). The 2008 revision of the WHO Classification of Myeloid Neoplasms and Acute Leukemia: rationale and important changes. Blood, Vol. 114, No.5, (July 2009), pp. 937-951, ISSN 0006-4971

Wang, Z.Y., \& Chen, Z. (2008). Acute promyelocytic leukemia: from highly fatal to highly curable. Blood, Vol. 111, No. 5 (March 2008), pp.2505-15, ISSN 0006-4971 


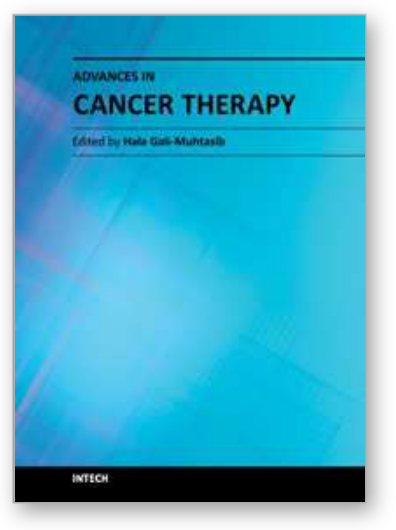

\author{
Advances in Cancer Therapy \\ Edited by Prof. Hala Gali-Muhtasib
}

ISBN 978-953-307-703-1

Hard cover, 568 pages

Publisher InTech

Published online 21, November, 2011

Published in print edition November, 2011

The book "Advances in Cancer Therapy" is a new addition to the Intech collection of books and aims at providing scientists and clinicians with a comprehensive overview of the state of current knowledge and latest research findings in the area of cancer therapy. For this purpose research articles, clinical investigations and review papers that are thought to improve the readers' understanding of cancer therapy developments and/or to keep them up to date with the most recent advances in this field have been included in this book. With cancer being one of the most serious diseases of our times, I am confident that this book will meet the patients', physicians' and researchers' needs.

\title{
How to reference
}

In order to correctly reference this scholarly work, feel free to copy and paste the following:

Irina Panovska-Stavridis (2011). Immunophenotyping of the Blast Cells in Correlations with the Molecular Genetics Analyses for Diagnostic and Clinical Stratification of Patients with Acute Myeloid Leukemia: Single Center Experience, Advances in Cancer Therapy, Prof. Hala Gali-Muhtasib (Ed.), ISBN: 978-953-307-703-1, InTech, Available from: http://www.intechopen.com/books/advances-in-cancer-therapy/immunophenotyping-ofthe-blast-cells-in-correlations-with-the-molecular-genetics-analyses-for-diagno

\section{INTECH}

open science | open minds

\section{InTech Europe}

University Campus STeP Ri

Slavka Krautzeka 83/A

51000 Rijeka, Croatia

Phone: +385 (51) 770447

Fax: +385 (51) 686166

www.intechopen.com

\section{InTech China}

Unit 405, Office Block, Hotel Equatorial Shanghai

No.65, Yan An Road (West), Shanghai, 200040, China

中国上海市延安西路65号上海国际贵都大饭店办公楼405单元

Phone: +86-21-62489820

Fax: +86-21-62489821 
(C) 2011 The Author(s). Licensee IntechOpen. This is an open access article distributed under the terms of the Creative Commons Attribution 3.0 License, which permits unrestricted use, distribution, and reproduction in any medium, provided the original work is properly cited. 